\title{
Oncolytic effects of the recombinant Newcastle Disease Virus, rAF-IL12, against colon cancer cells in vitro and in tumor- challenged NCr-Foxn1nu nude mice
}

\author{
Syed Umar Faruq Syed Najmuddin ${ }^{1,2}$, Zahiah Binti Mohamed Amin ${ }^{1,2}$, Sheau Wei Tan ${ }^{1,2}$, Swee Keong Yeap ${ }^{3}$, \\ Jeevanathan Kalyanasundram ${ }^{1}$, Abhimanyu Veerakumarasivam ${ }^{4}$, Soon Choy Chan ${ }^{5}$, Suet Lin Chia ${ }^{1,2}$, Khatijah \\ Yusoff $^{1,6}$, Noorjahan Banu Alitheen ${ }^{\text {Corresp. 1,2 }}$ \\ ${ }^{1}$ Universiti Putra Malaysia, Serdang, Malaysia \\ 2 Institute of Bioscience, Universiti Putra Malaysia, Serdang, Malaysia \\ 3 Xiamen University, Sepang, Malaysia \\ 4 Sunway University, Subang Jaya, Malaysia \\ 5 Perdana University, Serdang, Malaysia \\ 6 Malaysian Genome Institute, National Institute of Biotechnology Malaysia, Kajang, Malaysia \\ Corresponding Author: Noorjahan Banu Alitheen \\ Email address: noorjahan@upm.edu.my
}

Colon cancer remains one of the main cancers causing death in men and women worldwide as certain colon cancer subtypes are resistant to conventional treatments and the development of new cancer therapies remains elusive. Alternative modalities such as the use of viral-based therapeutic cancer vaccine is still limited, with only the herpes simplex virus (HSV) expressing granulocyte-macrophage colony- stimulating factor (GMCSF) or talimogene laherparepvec (T-Vec) being approved in the USA and Europe so far. Therefore, it is imperative to continue the search for a new treatment modality. This current study evaluates a combinatorial therapy between the oncolytic Newcastle disease virus (NDV) and interleukin-12 (IL-12) cytokine as a potential therapeutic vaccine to the current anti-cancer drugs. Several in vitro analyses such as MTT assay, Annexin V/FITC flow cytometry, and cell cycle assay were performed to evaluate the cytotoxicity effect of recombinant NDV, rAF-IL12. Meanwhile, serum cytokine, serum biochemical, histopathology of organs, and TUNEL assay were carried out to assess the anti-tumoral effects of rAF-IL12 in HT29 tumor-challenged nude mice. The apoptosis mechanism underlying the effect of rAF-IL12 treatment was also investigated using NanoString Gene expression analysis. The recombinant NDV, rAF-IL12 replicated in HT29 colon cancer cells as did its parental virus, AF2240-i. The RAF-IL12 treatment had slightly better cytotoxicity effects towards HT29 cancer cells when compared to the AF2240-i as revealed by the MTT, Annexin V FITC, and cell cycle assay. Meanwhile, the 28-day treatment with rAF-IL12 had significantly $(p<0.05)$ perturbed the growth and progression of $\mathrm{HT} 29$ tumor in $\mathrm{NCr}$ - 
Foxn1nu nude mice when compared to the untreated and parental wild-type NDV strain AF2240-i. The rAF-IL12 also modulated the immune system in nude mice by significantly $(p<0.05)$ increased the level of IL-2, IL-12, and IFN- $\gamma$ cytokines. Treatment with rAF-IL12 had also significantly $(p<0.05)$ increased the expression level of apoptosis-related genes such as Fas, caspase-8, BID, BAX, Smad3, and granzyme B in vitro and in vivo. Besides, rAF-IL12 intra-tumoral delivery was considered safe and was not hazardous to the host as evidenced in pathophysiology of the normal tissues and organs of the mice as well as from the serum biochemistry profile of liver and kidney. Therefore, this study proves that rAFIL12 had better cytotoxicity effects than its parental AF2240-i and could potentially be an ideal treatment for colon cancer in the near future. 
1 Oncolytic Effects of the Recombinant Newcastle

2 Disease Virus, rAF-IL12, against Colon Cancer Cells In

3 Vitro and in Tumor-challenged NCr-Foxn1nu Nude

4 Mice

Syed Umar Faruq Syed Najmuddin ${ }^{1,2}$, Zahiah Mohamed Amin ${ }^{1,2}$, Sheau Wei Tan ${ }^{1,2}$, Swee Keong Yeap $^{3}$, Jeevanathan Kalyanasundram ${ }^{1,2}$, Abhimanyu Veerakumarasivam ${ }^{4}$, Soon Choy Chan ${ }^{5}$, Suet Lin Chia ${ }^{1,2}$, Khatijah Yusoff ${ }^{1,6}$, Noorjahan Banu Alitheen ${ }^{1,2}$

${ }^{1}$ Universiti Putra Malaysia, Serdang, Malaysia

${ }^{2}$ Institute of Bioscience, Universiti Putra Malaysia, Serdang, Malaysia

${ }^{3}$ Xiamen University, Sepang, Malaysia

${ }^{4}$ Sunway University, Subang Jaya, Malaysia.

${ }^{5}$ Perdana University, Serdang, Malaysia.

${ }^{6}$ Malaysian Genome Institute, Kajang, Malaysia.

Corresponding Author:

20 Noorjahan Banu Alitheen ${ }^{1,2}$

21 Universiti Putra Malaysia, Serdang, Malaysia

22 Email address: noorjahan@upm.edu.my

\section{Abstract}

Colon cancer remains one of the main cancers causing death in men and women worldwide as certain colon cancer subtypes are resistant to conventional treatments and the development of new cancer therapies remains elusive. Alternative modalities such as the use of viral-based therapeutic cancer vaccine is still limited, with only the herpes simplex virus (HSV) expressing granulocyte-macrophage colony- stimulating factor (GM-CSF) or talimogene laherparepvec (TVec) being approved in the USA and Europe so far. Therefore, it is imperative to continue the search for a new treatment modality. This current study evaluates a combinatorial therapy between the oncolytic Newcastle disease virus (NDV) and interleukin-12 (IL-12) cytokine as a potential therapeutic vaccine to the current anti-cancer drugs. Several in vitro analyses such as MTT assay, Annexin V/FITC flow cytometry, and cell cycle assay were performed to evaluate the cytotoxicity effect of recombinant NDV, rAF-IL12. Meanwhile, serum cytokine, serum biochemical, histopathology of organs, and TUNEL assay were carried out to assess the antitumoral effects of rAF-IL12 in HT29 tumor-challenged nude mice. The apoptosis mechanism underlying the effect of rAF-IL12 treatment was also investigated using NanoString Gene expression analysis. The recombinant NDV, rAF-IL12 replicated in HT29 colon cancer cells as did its parental virus, AF2240-i. The rAF-IL12 treatment had slightly better cytotoxicity effects towards HT29 cancer cells when compared to the AF2240-i as revealed by the MTT, Annexin V FITC, and cell cycle assay. Meanwhile, the 28-day treatment with rAF-IL12 had significantly 
$43(\mathrm{p}<0.05)$ perturbed the growth and progression of HT29 tumor in NCr-Foxn1nu nude mice when 44 compared to the untreated and parental wild-type NDV strain AF2240-i. The rAF-IL12 also 45 modulated the immune system in nude mice by significantly $(\mathrm{p}<0.05)$ increased the level of IL-2, 46 IL-12, and IFN- $\gamma$ cytokines. Treatment with rAF-IL12 had also significantly $(p<0.05)$ increased 47 the expression level of apoptosis-related genes such as Fas, caspase-8, BID, BAX, Smad3, and 48 granzyme B in vitro and in vivo. Besides, rAF-IL12 intra-tumoral delivery was considered safe 49 and was not hazardous to the host as evidenced in pathophysiology of the normal tissues and 50 organs of the mice as well as from the serum biochemistry profile of liver and kidney. Therefore, 51 this study proves that rAF-IL12 had better cytotoxicity effects than its parental AF2240-i and 52 53

Keywords: Newcastle disease virus, apoptosis, HT29, colon cancer, and rAF-IL12

55

\section{6}

57

58

59

60

61

62

63

64

65

66

67

68

69

70

71

72

73

74

75

76

77

78

79

80

81

82

\section{Introduction}

A virus is a nanoscale particle $\left(<10^{-6} \mathrm{~mm}\right)$ that can infect the cells of a biological organism such as bacteria, mammals, or plants (Koudelka et al., 2015). It carries specific tools on its surface designed to cross the barriers of host cells before consequently delivering their nucleic acid cargo and hijacking the intracellular machinery to produce the components of progeny viruses (Koudelka et al., 2015). Engineered viruses may therefore be used in gene therapies aimed at influencing gene expression in living organisms through delivery of integrating or nonintegrating exogenous DNA or RNA to treat certain diseases (Riley \& Vermerris, 2017).

At the turn of the $19^{\text {th }}$ century, oncolytic viruses were identified as possible tumoricidal agents whereby body fluids containing human or animal viruses were used to infect cancer cells (Kelly \& Russell, 2007). Since then, various oncolytic viruses (OVs) such as the herpes simplex virus (HSV), adenovirus, reovirus, and the Newcastle disease virus (NDV) have been extensively studied for their potential use as anti-cancer agents (Alemany, 2014; Gong et al., 2016; Lam et al., 2011; Yin et al., 2017). Non-human viruses like the NDV are sought after as they could retain their oncolytic ability in a host not traditionally susceptible to that particular virus (i.e. viral adaptation for targeting) and at the same time considered to be non-infectious or nonpathogenic in humans. Successful use of the NDV has been demonstrated in various studies using strains such as the MTH68/H, LaSota, PV701, and AF2240-i (Kelly \& Russell, 2007; Lam et al., 2011). The NDV is an avian paramyxovirus that has a $15 \mathrm{~kb}$ single-stranded, negativesense and non-segmented RNA genome comprising six genes that encode for six structural proteins namely, the nucleocapsid protein $(\mathrm{NP})$, phosphoprotein $(\mathrm{P})$, fusion protein $(\mathrm{F})$, envelope matrix protein $(\mathrm{M})$, large protein $(\mathrm{L})$, and hemagglutinin-neuraminidase surface glycoprotein (HN) (Schirrmacher, 2017). NDV strains can be classified into three main pathotypes namely, the velogenic (highly virulent), mesogenic (intermediate), and lentogenic (non-virulent) strains (Zamarin \& Palese, 2012). 
83 The Malaysian viscerotropic-velogenic NDV strain, AF2240-i, was isolated by the Malaysian 84 Veterinary Research Institute (VRI) from a local field outbreak in the 1960s. Due to its high 85 virulence, it has been used as standard challenge virus for the development of local chicken 86 vaccine (Kalyanasundram et al., 2018). Interestingly, it has also been reported that this strain 87 exhibits both in vitro and in vivo oncolytic activity against breast, brain, and cervical cancer cells 88 as well as the non-adherent leukemic cells (Murulitharan et al., 2013). With regards to all the 89 oncolytic abilities possessed by the wild-type NDV, genetic engineering has paved its way to 90 maximise the therapeutic efficacy of NDV by arming them with immune-enhancing cytokines. 91 For instance, NDV Anhinga strain expressing interleukin-2 (IL-2) could effectively inhibit the 92 growth of hepatocellular carcinoma in vivo while rNDV-IL2-TRAIL could significantly enhance 93 the induction of apoptosis in cancer cells (Wu et al., 2016; Bai et al., 2014). Other researchers 94 have also utilized the NDV to express interleukine-7 (IL-7) and interleukine-15 (IL-15) in their 95 studies where the recombinant NDV strain LX/IL7/IL15 showed antitumor activity against 96 97 murine melanoma cells (Xu et al., 2018).

On a related note, the use of recombinant NDV is advantageous over the wild type strain as several studies have demonstrated that IL-12-expressing OVs improve the therapeutic index in pre-clinical tumor models and improve tumor clearance (Alkayyal, Mahmoud, \& Auer, 2016). IL-12 has long been touted as an ideal candidate for tumor immunotherapy due to its ability to activate both innate and adaptive immune system cells during antigen presentation (i.e. provide the bridge/interconnection between innate and adaptive immune system) by aiding the activation and regulation of several immune cells such as macrophages and natural killer cells (Lasek, Zagożdżon, \& Jakobisiak, 2014; Tsai et al., 2016; Tugues et al., 2015). IL-12 is a heterodimeric cytokine containing a $35 \mathrm{kDa}$ and a $40 \mathrm{kDa}$ subunit that is produced mainly by phagocytic cells such as dendritic cells and macrophages (also known as antigen-presenting cells, APCs) in response to antigenic stimulation. (Lee \& Margolin, 2011; Tugues et al., 2015). Furthermore, IL12 has previously been used as an immunomodulatory agent in recombinant virus such as adenovirus and efficiently manifested the anti-tumoral effect towards prostate cancer (Alkayyal et al., 2016).

112

In this study, we test the efficacy of recombinant AF2240-i expressing human interleukin-12 (rAF-IL12) in combating colon cancer cells by evaluating both in vitro and in vivo cytotoxicity effects of the rAF-IL12 against HT29 colon cancer cells, compared to the parental wild-type, AF2240-i. The utilisation of IL-12 in this study was due to the fact that IL-12 is a successful anti-tumor agent in previous preclinical studies (i.e applied in dozens of experimental models in 118 mice involving solid tumors and hematologic malignancies) (Lasek, Zagożdżon, \& Jakobisiak, 119 2014). IL-12 is also associated with the production and secretion of another potent anti-tumor 120 cytokines namely, interferon- $\gamma$ and interleukine-2 (Kalyanasundram et al., 2018). It is worth to mention that the rAF-IL12 virus is a genetically modified construct of the wild-type NDV strain AF2240-i through the insertion of IL-12 at the M and F intergenic junction, whereas the 
123 AF2240-i virus did not possess the IL-12 gene. In the previous study, the rAF-IL12 had been

124

125

126

127

128

129

130

131

132

133

134

135

136

137

138

139

140

141

142

143

144

145

146

147

148

149

150

151

152

153

154

155

156

157

158

159

160

161

162

proved to be stable as its concentration did not deteriorate when propagated in the embryonated chicken eggs from passage 1 (starting HA unit of $2^{8}$ ) until passage 10 (final HA unit of $2^{11}$ ). It showed a velogenic virulence nature as it had an intracerebral pathogenicity index (ICPI) of 1.78 (Amin et al., 2019). Other than that, the rAF-IL12 also showed cytotoxicity against breast cancer cell lines; MDA-MB-231 and MCF-7 (Amin et al., 2019).

\section{Materials \& Methods}

Preparation of cell culture

NIH/3T3 normal fibroblast and human HT29 colon cancer cell lines were purchased from the American Type Culture Collection (ATCC) USA. The 3T3 and HT29 cells were cultured in Dulbecco's Modified Eagle's Medium (DMEM) and Roswell Park Memorial Institute (RPMI) 1640 media, respectively. The media were supplemented with $10 \%$ fetal bovine serum (FBS) (Gibco, USA) and 1\% penicillin/streptomycin (Gibco, USA). The cell cultures were incubated in a humidified incubator at $37{ }^{\circ} \mathrm{C}$ in the presence of $5 \% \mathrm{CO}_{2}$ and were passaged/subcultured upon reaching $70 \%$ confluency as recommended by Yang et al., 2016.

\section{Preparation of virus}

The parental Malaysian viscerotropic NDV strain, AF2240-i, was used as negative control throughout this study. The rAF-IL12 virus was developed in the Virology Laboratory, Faculty of Biotechnology and Biomolecular Sciences, Universiti Putra Malaysia (Amin et al., 2019). The viruses were propagated in allantoic fluid of 9 to 11 day old SPF embryonated chicken eggs and were incubated at $37^{\circ} \mathrm{C}$ for $48-72 \mathrm{~h}$. The allantoic fluid was harvested and the titre of the virus was determined by the haemagglutinin assay (HA) using $1 \%$ chicken red blood cells. All in vitro assays were performed at 72 hours post infection (h.p.i.) (Amin et al., 2019).

\section{3- [4,5-dimethylthiazol-2-yl]-2,5 diphenyltetrazolium bromide (MTT) assay}

The half maximal inhibitory concentration $\left(\mathrm{EC}_{50}\right)$ of the virus towards cancer cells viability was assessed by the MTT assay based on the reduction of yellow tetrazole to purple formazan crystals. Briefly, a concentration of 80,000 cells/ $\mathrm{mL}$ was seeded into a 96 -well plate and incubated overnight before being infected with serially diluted virus on the following day. Upon reaching the 72 hours post infection (h.p.i.), MTT solutions were added before the formazan crystals were solubilized by DMSO. Finally, the absorbance at $570 \mathrm{~nm}$ wavelength of the microplate was analysed using the $\mu \mathrm{Quant}{ }^{\mathrm{TM}}$ enzyme-linked immunosorbent assay (ELISA) microplate reader (Bio-tek Instruments, USA) (Syed Najmuddin et al., 2016).

\section{qPCR validation of virus copy number}

RNA was extracted from the rAF-IL12-treated HT29 cells (72 h.p.i.) using TRI Reagent ${ }^{\circledR}$ (Sigma, USA). The yield and purity of RNA were assessed using Nanodrop machine (Eppendorf, 
163 USA) before qPCR validation of virus copy number was performed. A Taqman real-time PCR

164

165

166

167

168

169

170

171

172

173

174

175

176

177

178

179

180

181

182

183

184

185

186

187

188

189

190

191

192

193

194

195

196

197

198

199

200

201

202 protocol was carried out using the primers 5'- TCCGCAAGATCCAAGGGTCT- 3' and 5'CGCTGTTGCAACCCCAAG- 3' as well as the TaqMan probe 5'(FAM) AAGCGTTTCTGTCT CCTTCCTCCA (BHQ- 3', which target the fusion (F) gene of the NDV (Abdolmaleki et al., 2018). All qPCR reactions were performed in a final reaction volume of $20 \mu \mathrm{L}$ containing $1 \mathrm{x}$ iTaq universal probes reaction mix (Bio-Rad, USA), $0.5 \mu \mathrm{M}$ of each primer, $0.25 \mu \mathrm{M}$ of TaqMan probe, $1 \mathrm{U}$ of iScript reverse transcriptase, and $300 \mathrm{ng}$ of RNA. A negative control (i.e. without template RNA) was included in each run (Abdolmaleki et al., 2018).

\section{Tissue culture infectious dose (TCID $\left._{50}\right)$ assay}

A concentration of 8,000 cells/ well was seeded into a 96 -well plate and incubated overnight before being infected with 10 -fold serially diluted viruses on the following day. The infected cells were incubated for 5 days in a humidified incubator at $37{ }^{\circ} \mathrm{C}$ in the presence of $5 \% \mathrm{CO}_{2}$. Later, the $96-w e l l$ plate was stained with $1 \%$ crystal violet and the plate was observed under inverted microscope to spot the cytopathic effects caused by the virus. Data was calculated using the Reed and Muench method to determine the TCID $50 / \mathrm{mL}$ (Jiang et al., 2018).

\section{Annexin V FITC analysis}

The assay was carried out using Annexin V FITC Kit (BD Pharmigen, USA) according to manufacturer's protocol to evaluate the apoptosis induction of rAF-IL12 towards cancer cells. The pellets of rAF-IL12-treated HT29 cells (72-h post-infection) were resuspended in 1x Binding Buffer prior to staining with FITC Annexin V and propidium iodide (PI) dyes. The cell suspension was then allowed to stand in the dark at room temperature for 15 mins before being analysed using the NovoCyte Flow Cytometer (ACEA Biosciences Inc., USA) and the NovoExpress ${ }^{\circledR}$ version 1.2.4 software (ACEA Biosciences Inc., USA) (Pawłowska et al., 2018).

\section{Cell cycle analysis}

The rAF-IL12-treated HT29 cells (72-h post-infection) was subjected to cell cycle analysis using the Cycletest ${ }^{\mathrm{TM}}$ Plus DNA Reagent Kit (BD Biosciences, USA). The cells pellet was first resuspended in solution A (trypsin), followed by in solution B (RNAse A) and finally stained with PI dyes, which requires a 10 mins of incubation period in each step. Later, the mixture was analysed by NovoCyte Flow Cytometer (ACEA Biosciences Inc., USA) using NovoExpress ${ }^{\circledR}$ version 1.2.4 software (ACEA Biosciences Inc., USA) (Syed Najmuddin et al., 2016).

\section{In vivo animal study}

Approximately 5 to 6-week-old male NCr-Foxn1nu nude mice, weighing approximately $20 \mathrm{~g}$ were purchased from InVivos Pte Ltd, Singapore. All mice were housed in sterile micro-isolator (filter bonneted and ventilated) cages in the laboratory animal resources facility at the Comparative Medicine and Technology Unit (CoMeT), UPM complying to the standard condition outlined by the UPM ethics committee's guidelines for the care of laboratory animals. 
203 All mice were handled in humane and ethical manner and were housed under 12-h dark-light 204 cycle with an ambient temperature regulated at $\sim 28 \pm 2^{\circ} \mathrm{C}$. Sterilized or disinfected tap-water and 205 standard pellet diet were provided daily throughout the study period. There was no enrichment 206 provided throughout the study. Changing of bedding and litter tray was carried out twice a week. 207 Overdose of ketamine and xylazine $(200 \mathrm{mg} / \mathrm{kg}$ and $200 \mathrm{mg} / \mathrm{mL}$ per $\mathrm{kg}$ body weight, respectively) 208 was used to euthanise the mice to avoid or limit pain/distress in the animal. The mice were also 209 euthanised if, 1) severe body weight loss up to $10 \%$ in one week; 2) animal showing no 210 inclination to feed or drink; 3) tumor in mice appear to have a rupture; and 4) tumor size exceeds 211 the allowed range $(>2 \mathrm{~cm})$. However, no mice were euthanised prior to the planned end of the 212 experiment. Any surviving mice at the conclusion of the experiment were euthanized. This study 213 was approved by the International Animal Care and Use Committee, UPM (Reference Number: 214 UPM/IACUC/AUP/RO63/2017) and the experiments were conducted based on the approved 215 guidelines.

216

217 Cancer cell preparation and injection into mice

218 The HT29 human colon carcinoma cell line was used in this study and was harvested from $70 \%$ 219 confluent cell cultures. Cell suspensions were prepared in PBS to give approximately $1 \times 10^{7}$ cells/ $\mathrm{mL}$ for injection. To generate xenograft, $100 \mu \mathrm{L}$ of the HT29 cell suspension was injected at the subcutaneous site of the left hind leg of the NCr-Foxn1nu nude mice using a 27-gauge needle (Teruma, USA). The mice were observed daily until tumor masses develop $\left( \pm 50 \mathrm{~mm}^{3}\right)$.

\section{Treatment of the tumor-challenged nude mice}

The nude mice were grouped into four study groups, comprising one group of non-tumor bearing mice (Normal) and three groups of tumor-bearing mice. The three tumor-bearing mice groups were treated with $0.1 \mathrm{~mL}$ of PBS (Negative control), AF2240-i (1280 HA/mL), and rAF-IL12 $(1280 \mathrm{HA} / \mathrm{mL})$ respectively via intra-tumoral injections, twice a week for four cycles (i.e. 8 times in a 28-day treatment).

\section{Measurement of tumor growth}

Tumor size was estimated by measuring the greatest longitudinal diameter (length) and the greatest transverse diameter (width) using a Vernier calliper. Tumor volume was estimated using the standard formula by Kersemans et. al., (2013):

Tumor volume $\left(\mathrm{mm}^{3}\right)=0.5 \mathrm{x}$ length $\mathrm{x}(\text { width })^{2}$

\section{Tissue collection}

Whole blood and serum samples were collected for further analysis, while tissue samples such as tumors and vital organs (lung, spleen, liver, and kidney) were also harvested. Each tissue sample was cut into two halves, with one half placed in tube containing $10 \%$ buffered formalin for fixation and histopathology analysis and the other half placed in RNAlater solution (ThermoFisher Scientific, USA) and stored in $-80{ }^{\circ} \mathrm{C}$ freezer for subsequent molecular analysis. 


\section{Hematoxylin and eosin ( $\mathrm{H}$ \& E) histopathology staining}

245

246

247

248

249

250

251

252

253

254

255

256

257

258

259

260

261

262

263

264

265

266

267

268

269

270

271

272

273

274

275

276

277

278

279

280

281

282

The organs for histopathological examination were fixed in $10 \%$ buffered formalin and embedded in paraffin. For H\&E staining, the tissue was subjected to deparaffinization using xylene followed by rehydration using decreasing concentrations of ethanol (i.e. 100\%, 90\%, $80 \%$, and $70 \%$ ) before rinsing with tap water for 5 mins. The slides were then stained with the Harris Hematoxylin and counterstained with eosin. Finally, the slides were mounted with mounting media before observation under a bright-field microscope (Nikon, Japan) (Cardiff, Miller, \& Munn, 2014).

\section{Serum biochemical analysis}

To verify the status of liver and kidney function, concentration of enzymes and biomarker activities such as aspartate aminotransferase (AST), alkaline phosphates (ALP), alanine aminotransferase (ALT), and creatinine were measured. Serum from blood was analysed for its level of biochemical properties using the standard assay kits (Roche Diagnostic GmbH, USA), following the manufacturer's protocol (Abu et al., 2018).

\section{Serum detection of IL-2, IL-12, and IFN- $\gamma$ cytokines}

The expression of IL-2, IL-12, and IFN- $\gamma$ in mouse serum was measured using the quantitative enzyme-linked immunosorbent assay (ELISA) kits purchased from Biolegend, USA, following the manufacturer's protocol. Colorimetric analysis was conducted by measuring absorbance at $450 \mathrm{~nm}$ and $570 \mathrm{~nm}$ wavelengths using the $\mu$ Quant ELISA microplate reader (Bio-Tek Instruments, USA).

\section{NanoString gene expression analysis}

The gene expression analysis of tumor RNA was conducted according to the manufacturer's guide of the nanoString nCounter TagSet Elements ${ }^{\mathrm{TM}}$. A volume of $8 \mu \mathrm{L}$ of master mix (TagSet, hybridization buffer, $0.6 \mathrm{nM}$ probe $\mathrm{A}$, and $3 \mathrm{nM}$ probe $\mathrm{B}$ ) was transferred into the hybridization/strip tubes and $7 \mu \mathrm{L}$ of RNA sample was added. Hybridization was conducted by incubating the mixtures at $67{ }^{\circ} \mathrm{C}$ for $16 \mathrm{~h}$ in a thermal cycler. The samples were then, inserted into the Prep Station machine for purification and immobilization onto the internal surface of a sample cartridge for about $2 \mathrm{~h}$ before being transferred to a Digital Analyzer machine for imaging and analysis of gene expression.

\section{TUNEL assay}

The degree of apoptosis induction of treatments was determined using the DeadEnd ${ }^{\mathrm{TM}}$ colorimetric TUNEL System (Promega, USA) according to the manufacturer's protocol. The paraffin was removed from the embedded tumor-sectioned slides by immersing them into xylene, followed by rehydration using graded ethanol (100\%, 95\%, 85\%, 70\%, and 50\%), and fixation using $4 \%$ paraformaldehyde. Tissue sections were subsequently permeabilized using 
283 Proteinase $\mathrm{K}$ and equilibrated using equilibration buffer. Fragmented DNA was labelled by 284 incubation with rTdT mixture and $2 \mathrm{x}$ SSC termination solvent was used to terminate the 285 reaction. The slides were then, incubated with streptavidin HRP followed by incubation with 286 substrate solution (DAB) for colorimetric detection. The slides were mounted with glycerol and

287

288

289

290

291

292

293

294

295

296

297

298

299

300

301

302

303

304

305

306

307

308

309

310

311

312

313

314

315

316

317

318

319

320

321

322 examined under bright-field inverted microscope (Nikon, Japan) (Ben-Izhak et al., 2007).

\section{Statistical analysis}

All experiments were evaluated using one-way ANOVA on the GraphPad Prism 7 software (GraphPad Software Inc., USA). All in vitro and in vivo tests were carried out in three replicates and the results are expressed as mean \pm standard error of mean (S.E.M.). Significance values of $p$ $<0.05$ were considered as statistically significant.

\section{Results}

\section{Viral replication kinetics of rAF-IL12 inside HT29 cancer cells}

Viral replication/growth kinetics of rAF-IL12 in HT29 cells was assessed by quantifying viral copy number through TaqMan real-time PCR using total RNA extracted from infected HT29 cells at 24, 48, and 72 hpi. Based on Figure 1, the rAF-IL12 showed significantly $(\mathrm{p}<0.05)$ higher viral copy number in HT29, indicating higher replication/growth kinetics in HT29 cells, compared to AF2240-i. This indicated that the incorporation of IL-12 gene into the AF2240-i anti-genome did not disrupt the resulting ability of the recombinant rAF-IL12 to replicate in neoplastic cells.

\section{$\mathrm{TCID}_{50}$ of viruses in $\mathrm{HT} 29$ cells}

Table 1 represents data of TCID T0 $_{0}$ of the AF2240-i and rAF-IL12 viruses in HT29 cancer cells. From these data, the infectivity dose/titre of the AF2240-i and rAF-IL12 were $3.16 \times 10^{4}$ $\mathrm{TCID}_{50} / \mathrm{mL}$ and $4.68 \times 10^{4} \mathrm{TCID}_{50} / \mathrm{mL}$, respectively. The results indicated that the rAF-IL12 had higher number of infectious virus particles per volume when compared to the AF2240-i.

\section{Induction of apoptosis by rAF-IL12 in vitro}

MTT assay was conducted to assess the cytotoxic effects of parental AF2240-i and rAF-IL12 on HT29 colon cancer cell line (Figure 2). Based on Table 2, infection of HT29 with rAF-IL12 resulted in lower $\mathrm{EC}_{50}$ compared to infection with the parental $\mathrm{AF} 2240-\mathrm{i}\left(\mathrm{EC}_{50}=110 \pm 0.58 \mathrm{HA}\right.$ unit vs. $\mathrm{EC}_{50}=128 \pm 1.16 \mathrm{HA}$ unit), indicating that rAF-IL12 showed significantly $(\mathrm{p}<0.05)$ better anti-proliferative effect against HT29 cells compared to AF2240-i. Nevertheless, both AF2240-i and rAF-IL12 did not inhibit the growth of normal fibroblast 3T3 cells. The ability of rAF-IL12 to cause cancer cell death or apoptosis was further examined by Annexin V/FITC staining assay and flow cytometry analysis. Figure 3 showed the results of Annexin V/FITC staining of the virus infected HT29 cells. There was a cell population percentage shifting from viable cells to early apoptotic to late apoptotic cells (Figure 3A-C). The percentage of early apoptotic cells increased from $0.06 \% \pm 0.01 \%$ in the negative control group to $8.34 \% \pm 0.14 \%$ in AF2240-i-treated cells and $9.03 \% \pm 0.69 \%$ in rAF-IL12-treated cells. The percentage of late 
323

324

325

326

327

328

329

330

331

332

333

334

335

336

337

338

339

340

341

342

343

344

345

346

347

348

349

350

351

352

353

354

355

356

357

358

359

360

361

362

apoptotic cells was even higher in both AF2240-i- and rAF-IL12-treated cells $(9.08 \% \pm 0.09 \%$ and $11.20 \% \pm 0.40 \%$, respectively) whereas no cell population entered the late apoptotic phase among the negative control group. To investigate the effects of AF2240-i and rAF-IL12 on the cell cycle progression in HT29 cells, the FACS cell cycle analysis was performed. As shown in Figure 4, the percentage of HT29 cells at the $\mathrm{G}_{0}$ phase increased significantly from $0.97 \% \pm 0.11 \%$ in the negative control group to $8.08 \% \pm 0.85 \%$ and $11.07 \% \pm 0.73 \%$ in AF 2240 -iand rAF-IL12-treated groups, respectively whereas a substantial decrease of the percentage of cells from $76.26 \% \pm 0.26 \%$ in the negative control group to $69.71 \% \pm 1.26 \%$ (AF2240-i) and $68.06 \% \pm 0.82$ (rAF-IL12) was observed at the $\mathrm{G}_{1}$ phase.

\section{rAF-IL12 inhibited the growth of HT29 tumor}

The therapeutic effects of the rAF-IL12 treatment in nude mice bearing the HT29-induced tumors were assessed after 28 days of treatment. Based on Figure 5A, the size of tumor in rAFIL12-treated group was observed to be the smallest compared to negative control and AF2240-i treated group. As shown in Figure 5B, the line graph plot of tumor volume growth throughout the 28 days post treatment, revealed that the growth of tumor treated with rAF-IL12 was the most restricted compared to the AF2240-i-treated and untreated groups. The final mean tumor volume of mice treated with rAF-IL12 was the smallest $\left(321.54 \pm 22.90 \mathrm{~mm}^{3}\right)$ when compared to the negative control $\left(1649.38 \pm 138.10 \mathrm{~mm}^{3}\right)$ and the AF2240-i-treated $\left(577.87 \pm 60.96 \mathrm{~mm}^{3}\right)$ groups. Based on Figure 5C, the rAF-IL12-treated group showed the least tumor weight $(0.40 \pm 0.03 \mathrm{~g})$ compared to the negative control $(1.29 \pm 0.05 \mathrm{~g})$ and the AF2240-i-treated $(0.82 \pm 0.06 \mathrm{~g})$ groups. These results indicated that rAF-IL12 treatment of HT29 tumor mass resulted in the slowest growth rate and the lightest tumor weight compared to AF2240-i treatment and the negative control.

\section{rAF-IL12 replicated inside tumor, lung, and spleen.}

The capability of rAF-IL12 in replicating inside tumor and organs tissues was evaluated using TaqMan real-time PCR through amplification of the NDV F gene. As shown in Figure 6, the rAF-IL12-treated group showed higher viral copy number in tumor and lung $\left(9.36\left(\log _{10}\right)\right.$ and $6.42\left(\log _{10}\right)$, respectively) compared to the AF2240-i-treated group $\left(8.97\left(\log _{10}\right)\right.$ and $6.16\left(\log _{10}\right)$, respectively). On the other hand, the AF2240-i-treated group showed higher viral copy number in spleen $\left(6.74\left(\log _{10}\right)\right)$ compared to the rAF-IL12-treated group $\left(5.47\left(\log _{10}\right)\right)$.

\section{Histopathological Safety Assessment of Organs (Lung, Spleen, Kidney, and Liver)}

Figure 7 shows a photomicrograph of the lungs stained with H\&E from the normal, untreated, and treatment groups (AF2240-i and rAF-IL12). Treatment groups and the untreated group had normal alveoli structure comparable to the lungs in the normal group. However, lungs in the AF2240-i-treated group had mild thickening of alveolar interstitial wall due to leucocytic infiltration. This indicated that treatment with rAF-IL12 did not affect the lung structure and function. Figure 8 shows a photomicrograph of histopathological assessment of the spleen from 
363

364

365

366

367

368

369

370

371

372

373

374

375

376

377

378

379

380

381

382

383

384

385

386

387

388

389

390

391

392

393

394

395

396

397

398

399

400

401

402

the normal, untreated, and treatment groups (AF2240-i and rAF-IL12). AF2240-i- and rAF-IL12treated samples showed a normal architecture of spleen with distinct separation of white pulp and red pulp structure similar to spleen in the normal nude mice group. However, depletion of lymphocyte due to degeneration of white pulp area as well as poor distinction between red pulp and white pulp were observed in the spleen of the untreated group. These observations indicated that the rAF-IL12 and AF2240-i treatment did not cause any abnormalities towards spleen as opposed to the spleen in the untreated group. Photomicrographs of histopathological assessment of the kidney from normal, untreated, and treatment groups (AF2240-i and rAF-IL12) are shown in Figure 9. HT29 tumor-burdened nude mice treated with AF2240-i and rAF-IL12 showed normal kidney architecture (i.e. comparable to the normal group), without obvious pathological lesions whereas the negative control/untreated group had an abnormal form of renal corpuscle with the size of the Bowman's space appearing to be smaller than the kidney from the other groups. Leucocytic infiltrations were also observed in the kidney interstitial space of the untreated and AF2240-i-treated groups. This indicated that treatment with rAF-IL12 did not affect kidney structure and function when compared to the ones in the untreated group. Histopathological assessment of liver of the HT29 tumor-burden mice treated with AF2240-i and rAF-IL12 as well as the untreated group did not show any obvious degeneration of hepatocytes or liver damage (Figure 10). However, liver metastasis and leucocytic infiltrations were observed in the untreated and AF2240-i-treated groups. These observations indicated that rAF-IL12 treatment could prevent liver metastasis from occurring in comparison to the AF2240-i-treated and untreated groups.

\section{rAF-IL12 did not interfere with kidney and liver enzymes function}

In this study, ALP, AST, ALT, and creatinine serum levels were evaluated to determine the liver and kidney function following rAF-IL12 treatment on colon cancer-challenged nude mice. Our experiments revealed significant $(\mathrm{p}<0.05)$ elevations of ALP, AST, ALT, and creatinine levels in the negative control/untreated tumor-bearing mice group in comparison to the normal group (Table 3). However, there were significant decrease $(\mathrm{p}<0.05)$ in ALP, AST, ALT, and creatinine levels in the tumor-bearing mice group receiving the rAF-IL12 treatment compared to the negative control/untreated mice. Thus, it can be suggested that rAF-IL12 did not cause any adverse effects towards the liver and kidney function and might as well protect those organs from abnormal expression level of serum caused by cancer cells.

\section{rAF-IL12 modulated the immune system through IL-2, IL-12, and IFN- $\gamma$ cytokines}

Immunomodulation potential of rAF-IL12 in the HT29 tumor-challenged mice was carried out by measuring the expression levels of IL-12, IL-2, and IFN- $\gamma$ cytokines. Based on Figure 11A, IL-12 serum cytokine was not detected in all the mice groups except in the tumor-bearing mice receiving rAF-IL12 treatment. A similar pattern was observed in the IFN- $\gamma$ expression (Figure $11 \mathrm{C})$. As shown in Figure 11B, there was a significant increase $(\mathrm{p}<0.05)$ of IL-2 level in rAFIL12-treated mice $(21.03 \mathrm{pg} / \mathrm{mL})$ when compared to the negative control/untreated $(3.45 \mathrm{pg} / \mathrm{mL})$

Peer) reviewing PDF | (2020:04:47395:2:0:NEW 21 Jul 2020) 
403 and AF2240-i treated mice $(15.17 \mathrm{pg} / \mathrm{mL})$, whereas none was detected in the normal mice. 404 Therefore, our results show that rAF-IL12 could regulate all the aforementioned cytokines by 405 increasing their expression levels, which are important in combatting cancer.

406

407

408

409

410

411

412

413

414

415

416

417

418

419

420

421

422

423

424

425

426

427

428

429

430

431

432

433

434

435

436

437

438

439

440

441

442

\section{rAF-IL12 treatment increased the expression level of apoptosis-related genes}

NanoString nCounter TagSet Elements ${ }^{\mathrm{TM}}$ gene expression analysis was carried out to measure the expression level of pro-apoptotic genes (Fas, caspase-8, BID, BAX, SMAD3, and granzyme B). The expression levels of the genes are shown in Figure 12, where rAF-IL12 treatment significantly $(\mathrm{p}<0.05)$ increased the expression levels of Fas, caspase-8, BID, BAX, and SMAD3 in vitro and in vivo when compared with the negative control group. Granzyme B expression level was also significantly $(\mathrm{p}<0.05)$ increased in the tumor-burdened nude mice treated with rAF-IL12.

rAF-IL12 treatment increased the number of apoptotic cells in TUNEL assay and decreased the number of mitotic cells of the H\&E stained tumor

In situ chromatin fragmentation/apoptosis event was confirmed by TUNEL staining of the sectioned tumors of the negative control, positive control, AF2240-i-treated, and rAF-IL12treated groups obtained from the HT29 tumor-bearing nude mice. TUNEL-stained sections of the rAF-IL12-treated group (60.33) showed clusters of numerous dark brown apoptotic nuclei in the tumor comparable to those in the positive control group (i.e. sectioned tumor treated with DNase I) (64.67). The TUNEL-positive apoptotic nuclei were lesser in the AF2240-i-treated group (30.33) while the negative control had the least number of TUNEL-positive apoptotic nuclei appeared in the tumor tissue (7.67) as shown in Figure 13. Based on Figure 14, the rAF-IL12 treatment group had the least number of actively dividing cells (i.e. undergoing mitosis) (18.67) compared to the AF2240-i-treated (25.00) and the untreated groups (37.67).

\section{Discussion}

Colorectal cancer (CRC) remains a worldwide burden and is expected to continue to rise to more than 2.2 million new cases and 1.1 million deaths by 2030 (Arnold et al., 2017). Current chemotherapy and radiotherapy available for colorectal cancer have so far shown limited efficiency due to adverse side effects and emergence of drug resistance among treated patients (Sveen et al., 2018). These issues are particularly due to the heterogeneity of colorectal cancer that involves various genetic and epigenetic alterations, resulting in distinct morphological and phenotypic differences among cases that respond differently to therapy (Gang et al., 2018; Merlano et al., 2017). The HT29 colon cancer cell line has generally been used for the analysis of oncolytic viruses (Boisgerault et al., 2013; Kojima et al., 2010). It possesses the wild-type KRAS gene and mutated BRAF gene at V600E site, a condition that contributes to resistance towards anti-EGFR therapy such as cetuximab and panitumumab (Ahmed et al., 2013; Linnekamp et al., 2015; Zhao et al., 2017). Other than that, HT29 is classified as a CMS3 
443 subtype CRCs, which is devoid of immune cell infiltration and is also microsatellite stable 444 (MSS), reflecting its low response to immunotherapy (Guinney et al., 2016; Kang et al., 2018; 445 Kocarnik, Shiovitz, \& Phipps, 2015; Rozek et al., 2016).

446

447

448

449

450

451

452

453

454

455

456

457

458

459

460

461

462

463

464

465

466

467

468

469

470

471

472

473

474

475

476

477

478

479

480

481

482

In this study, the efficacy of the recombinant NDV, rAF-IL12 in targeting the HT29 colon cancer cell was evaluated. The rAF-IL12 was developed by incorporating the IL-12 in the backbone of the wild-type AF2240-i genome to elicit better cancer therapeutic effects. Of note, the infectivity of virus plays a significant role in targeting cancer cells. The $\mathrm{TCID}_{50}$ titration method revealed that the rAF-IL12 had higher number of infectious virus particles per volume when compared to the AF2240-i, hence, indicating the higher infectivity possessed by the rAF-IL12 towards HT29 cells. This was in line with the results shown by the TaqMan real-time PCR as the rAF-IL12 showed higher growth/replication kinetics in HT29 cells compared to AF2240-i. Furthermore, the rAF-IL12 showed slightly greater cytotoxicity effects towards HT29 cells when compared to the AF2240-i as shown in the MTT assay and was further confirmed through Annexin V FITC and cell cycle analysis. Interestingly, it is of importance to note that the ability of NDV to selectively replicate and cause death in cancer cells is due to defective anti-viral signaling pathways among tumor cells which makes them highly susceptible to NDV (Goldufsky et al., 2013). In the previous study, the rAF-IL12 has been shown to significantly inhibit the proliferation and induce cytotoxicity against breast cancer cell lines; MDA-MB-231 and MCF-7 in vitro when compared to its parental wild-type AF2240-i (Amin et al., 2019). Cytotoxicity against colon and breast cancer indicates the capability and potential of rAF-IL12 in targeting other types of cancer as well.

Following the promising results in vitro, further evaluation of rAF-IL12 was carried out in vivo, using the NCr-Foxn1nu nude mice xenografted with HT29 cell line. This study showed that rAFIL12 significantly $(p<0.05)$ decreased the volume and weight of HT29 tumors when compared with the parental NDV, AF2240-i and the untreated group. This current finding was in line with Amin et al., (2019) where the rAF-IL12 treatment resulted in 52\% growth inhibition of 4T1 breast tumor while AF2240-i only caused 34.5\% inhibition as compared to the negative control group. This indicates that the rAF-IL12 was far more potent in inhibiting the growth and progression of cancer than its wild-type AF2240-i. However, it is of importance to note that the recombinant NDV, rAF-IL12 was able to inhibit the early stage of tumor growth in mice but the effect on the late stage is not covered in this study and definitely is important to be determined in the future. Other than that, it is also important to determine the possibility of re-growth of the tumor after 28 days when the virus is no longer injected. This study would exhibit the potential ability possessed by the recombinant NDV, rAF-IL12 in preventing the recurrence of colon cancer in the future. In addition to its tumor-suppressing effect, the safety aspects of the usage of rAF-IL12 as a tumor vaccine treatment in colon cancer-challenged mice were also evaluated by quantifying the viral copy number in tumor and vital organs such as lung, spleen, liver, and kidney. Higher viral copy number of rAF-IL12 in solid tumor indicates that rAF-IL12 exhibits 
483 higher tumor specific replication compared to its parental strain. Moreover, this result further 484 proves that rAF-IL12 was capable to replicate not just in the cancer cell line but also in the tumor 485 tissue. The intra-tumoral-injected rAF-IL12 and AF2240-i was found to disseminate to lung and 486 spleen with low viral copy number detected in both organs, while no viral presence was detected 487 in kidney and liver. This suggests that the use of the viruses had minimal impact towards normal 488 tissues and could be considered safe. Moreover, limited viral dissemination from injected tumor

489

490

491

492

493

494

495

496

497

498

499

500

501

502

503

504

505

506

507

508

509

510

511

512

513

514

515

516

517

518

519

520

521

522 mass into other organs is crucial for effective oncolytic activity, since the disseminated virus would be eliminated by antiviral activities of the interferons, cytokines and infiltrating leukocytes (Bian et al., 2006). Furthermore, histopathology analysis of the sectioned lung, spleen, liver, and kidney showed that rAF-IL12 did not cause any obvious pathological lesion. The aforementioned organs are often selected for preliminary toxicity observation in mice (Jing et al., 2014; Zhang et al., 2016; Yu, Drisco, \& Chen, 2013). It has been elucidated that malignancies contribute to elevated level of serum biochemistry parameters such as aspartate transaminase (AST), alanine transaminase (ALT), alkaline phosphatase (ALP), and creatinine whereby these enzymes were indicators for liver and kidney injuries (Chauhan et al., 2016; Kim et al., 2008; Saif, Alexander, \& Wicox, 2005). In this study, all the aforementioned enzymes levels were elevated in the untreated tumor-challenged nude mice in comparison to the level in the normal nude mice (without tumor) group. However, the enzyme levels in the rAF-IL12treated group were the closest to the normal nude mice group, rendering the intra-tumoral injection of rAF-IL12 to have very minimal/limited toxicity towards liver and kidney function. Our results are in agreement with a previous study in which the serum biochemistry level of AST and ALT were elevated on day-1 but normalized by day- 3 while creatinine levels remained normal at both day-1 and day-3 following the administration of NDV(F3aa)-GFP intraperitoneally to treat gastric cancer (Song et al., 2010).

The rAF-IL12, like any other NDV, could invoke specific host immune response against tumor tissue. In addition to the processed antigen at major histocompatibility complex I (MHC-I), immune cells could also target the viral envelop protein HN on the surface of the rAF-IL12infected tumor hence, could prevent the cancer from escaping the immune destruction through the downregulation of MHC-I expression as shown in previous studies ( Zakay-Rones, Tayeb,, \& Panet, 2015; Schirrmacher, 2017; Al-shamery et al., 2011; Pan et al., 2013). . Therefore, for a better understanding of a possible immunological effect of rAF-IL12 on HT29 xenografts in nude mice, the level of several important cytokines such as interleukin-12, interleukin-2, and IFN- $\gamma$ were evaluated. The data revealed that the expression levels of all the tested cytokines were significantly $(\mathrm{p}<0.05)$ upregulated in comparison to the untreated group following tumor colonization by the rAF-IL12. Interestingly, despite invoking the same immune response as the parental AF2240-i, the IL-12 expression of rAF-IL12-infected tumor mass could enhance its in vivo oncolytic activity and edging out the AF2240-i as rAF-IL12 treatment was the only group that managed to elicit the expression of IL-12 and IFN- $\gamma$ cytokines in the nude mice. Additionally, rAF-IL12 increased the expression level of IL-2 by 1.39 -fold when compared to 
523 the AF2240-i. This could only serve as an evidence for significant difference in suppressive 524 effect of tumor growth between rAF-IL12 and AF2240-i treatment. IL-12 and IFN- $\gamma$ presence is 525 important for anti-tumoral effect of rAF-IL12 as previous studies demonstrated that IL-12 526 treatment inhibited lung tumor growth, resulting in the long-term survival of lung cancer-bearing 527 mice while IFN- $\gamma$ mediated the anti-tumor effects of radiation therapy in murine colon tumor 528 (Gerber et al., 2013; Yue et al., 2016). IL-12 has also been shown to enhance natural killer (NK)529 cell mediated (i.e. innate immunity) cytotoxicity against tumor (Parihar et al., 2002), possibly 530 explaining the efficacy of the rAF-IL12 in limiting the progression of HT29 cancer cells in this 531 study (i.e. nude mice lack T-cells). Previous studies have shown that oncolytic adenovirus co532 expressing IL-12 and IL-18 led to the infiltration of NK cells into melanoma tumor tissues in murine models, while in another study, the efficacy of Sindbis-virus-based vectors against human ovarian carcinoma xenografts was found to be largely NK-cell-dependent and enhanced by IL-12 arming (Choi et al., 2011; Granot et al., 2011). Therefore, this suggests that the rAFIL12 could possibly enhance the infiltration of NK cells and innate immunity as well. Briefly, the fact that recombinant NDV, rAF-IL12 encodes for the IL-12 gene has made it possible for the generation/production of IL-12 cytokine in abundance during the viral replication process hence, further stimulating the immune response machinery towards cancer, something that could not be achieved by the parental AF2240-i. In this regard, the AF2240-i falls behind compared to the rAF-IL12. The increased level of the aforementioned cytokines as a result of rAF-IL12 treatment had successfully reversed the immunosuppressive tumor microenvironment and thereby, reinstating immunosurveillance, which ultimately resulted in the suppressed tumor growth of HT29 colon cancer-challenged nude mice (Kalyanasundram et al., 2018; Rausalova \&

545 Krepela, 2010).

546

547

Severely damaged cells are directed into a programmed cell death through either extrinsic or intrinsic (i.e. mitochondrial) pathway depending on the source of stimuli (Elmore, 2007). In this study, the expression level of pro-apoptotic genes such as the Fas receptor, initiator caspase-8, Bid, and Bax were elevated suggesting that rAF-IL12 induced apoptosis through extrinsic and intrinsic pathways. In extrinsic pathway, the binding of Fas ligand to Fas cell surface death receptors induces the formation of the death inducing signaling complex (DISC) followed by the activation of caspase- 8 that eventually cleaves and activates the effector caspase- 3 and -7 to

554

555

556

557

558

559

560

561

562 finally result in apoptosis (Elmore, 2007). Caspase-8 also provides a molecular link between the extrinsic and intrinsic apoptotic pathways whereby it cleaves the pro-apoptotic Bcl-2 family member, Bid, into a $15 \mathrm{kDa}$ protein, namely, truncated Bid (tBid). In its activated form, tBid heterodimerizes with Bax and subsequently inducing mitochondrial outer membrane permeabilization (MOMP) in cells, which later results in the release of cytochrome c into cytosol. The binding of cytochrome $\mathrm{c}$ to cytosolic Apaf-1 results in the formation of apoptosome, which then leads to the activation of caspases and subsequently, cell death (Kantari \& Walczak, 2011; Westphal et al., 2011). Previous studies have shown that the loss of Bax and caspase-8 expression in tumor cells are not only causing evasion of apoptosis but are also correlated with 
563 resistance to drug-induced apoptosis treatment as well as giving shorter survival time in cancer 564 patients (Paul-Samojedny et al., 2005; Pryczynicz et al., 2014; Sträter et al., 2010). Additionally, 565 rAF-IL12 was shown to also increase the expression level of Smad3, which is known to be 566 involved in inhibiting survival, proliferation, and tumorigenesis in colon cancer in response to 567 transforming growth factor- $\beta$ (TGF- $\beta$ ) stimulation. Previous studies have demonstrated that 568 inhibition of Insulin Receptor Substrates-1 (IRS-1) by TGF- $\beta /$ Smad3 leads to suppression of X569 linked inhibitor of apoptosis protein (XIAP) and cyclin D1 that are responsible for inhibiting 570 caspases, leading to apoptosis evasion. Additionally, Smad3 activates the pro-apoptotic protein, 571 Bad, which consequently results in TGF- $\beta$-mediated induction of apoptosis (Bailey et al., 2017; 572 Mithani et al., 2004). Other than that, serine proteinase granzyme B was also significantly up573 regulated by rAF-IL12 treatment. Granzyme B together with perforin granules are released by 574 cytotoxic T-lymphocytes and natural killer (NK) cells to eliminate harmful target cells including 575 virally infected, allogenic, and transformed cells (Mhaidat et al., 2014). In this study, it is 576 plausible to assume that the IL-12 from rAF-IL12 stimulates the production of granzyme B 577 through the NK cells as nude mice lack cytotoxic CD8 T-cells (due to lack of thymus). Perforin 578 disrupts the lipid membrane of the target cells by forming pores, which affects cellular fluidity 579 and content as well as providing the entry for granzyme B (Li et al., 2014; Mhaidat et al., 2014). 580 Once granzyme B is translocated into the target cell cytoplasm it can initiate cell apoptosis in 581 multiple ways, including direct proteolytic processing and activation of the executioner 582 procaspase-3 and -7, cleaves multiple intracellular housekeeping proteins such as $\alpha$-tubulin, 583 filamin, and $\beta$-fodrin, and altering the outer mitochondrial membrane through conversion and 584 activation of protein Bid to the MOMP-inducing tBid fragment (Rausalova \& Krepela, 2010). 585 The importance of granzyme B expression is justified by previous study which demonstrated that 586 low expression of granzyme B was associated with early signs of metastasis in CRC while higher tumor infiltration with CTL and granzyme B improved all-cause and cancer specific survival of

588

589

590

591

592

593

594

595

596

597

598

599

600

601

602 CRC patients, irrespective of stage (Prizment et al., 2017; Salama et al., 2011). However, it is also of importance that the expression levels of the aforementioned genes in the normal cell lines or normal mice to be determined as to further prove the recombinant NDV does not cause any apoptosis in non-cancerous cells. The induction of apoptosis by rAF-IL12 could also be observed by the TUNEL assay whereby higher number of DNA fragmentation was observed in the rAFIL12 treated group as compared to the negative control and AF2240-i treated groups. It is a good indicator as DNA fragmentation is one of the vital features in apoptotic event (Elmore, 2007). Further evidence in favor of rAF-IL12 as anti-cancer vaccine was the decreased number of actively dividing cells (mitotic cells) as portrayed by the sectioned tumor tissues stained with hematoxylin and eosin.

\section{Conclusions}

In conclusion, this study suggested that rAF-IL12 has promising anti-cancer potential especially in treating CMS3 subtype colorectal cancer as it was able to cause cell death in vitro and inhibit 
603 the growth of HT29 tumors in vivo while exhibiting a safety profile with no side effect towards

604

605

606

607

608

609

610

611

612

613

614

615

616

617

618

619

620

621

622

623

624

625

626

627

628

629

630

631

632

633

634

635

636

637

638

639

640

641

642

643

644

645

646

normal tissues and organs of HT29 tumor-challenged nude mice. Additionally, rAF-IL12 regulated the immune system of the tumor-burdened nude mice and increased the expression levels of apoptosis-related genes.

\section{Acknowledgements}

We thank all the Science Officers and staff at the Laboratory of Vaccine \& Immunotherapeutics (LIVES), UPM for their assistance with this study. A sincere gratitude goes to Dr. Ng Wei Lun for his assistance with proofreading and language editing of this manuscript. We would also like to thank the Attending Veterinarian and staff at the Comparative Medicine and Technology Unit (COMeT), UPM for granting us access to the facility and resources there.

\section{References}

Abdolmaleki, M., Yeap, S. K., Tan, S. W., Satharasinghe, D. A., Bello, M. B., Jahromi, M. Z., ... Ideris, A. (2018). Effects of Newcastle Disease Virus Infection on Chicken Intestinal Intraepithelial Natural Killer Cells. Frontiers in Immunology, 9(June), 1-10.

Abu, N., Zamberi, N. R., Yeap, S. K., Nordin, N., Mohamad, N. E., Romli, M. F., ... Alitheen, N. B. (2018). Subchronic toxicity, immunoregulation and anti-breast tumor effect of Nordamnacantal, an anthraquinone extracted from the stems of Morinda citrifolia L. BMC Complementary and Alternative Medicine, 18(1), 1-10.

Ahmed, D., Eide, P. W., Eilertsen, I. A., Danielsen, S. A., Eknæs, M., Hektoen, M., ... Lothe, R. A. (2013). Epigenetic and genetic features of 24 colon cancer cell lines. Oncogenesis, 2, 1-8.

Al-shamery, A. M., Yaseen, N. Y., Alwan, M. J., \& Al-shamery, A. M. (2011). Immunology study for NDV treatment in mice Bearing mammary adenocarcinoma tumor. Iraqi Journal of Cancer and Medical Genetics, 4(1), 11-21.

Alemany, R. (2014). Oncolytic Adenoviruses in Cancer Treatment. Biomedicines, 2(1), 36-49.

Alkayyal, A. A., Mahmoud, A. B., \& Auer, R. C. (2016). Interleukin-12-expressing oncolytic virus: A promising strategy for cancer immunotherapy. Journal of Taibah University Medical Sciences, 11(3), 187-193.

Amin, Z. M., Alhapis, M., Ani, C., Tan, S. W., Yeap, S. K., Alitheen, N. B., ...

Veerakumarasivam, A. (2019). Evaluation of a Recombinant Newcastle Disease Virus

Expressing Human IL12 against Human Breast Cancer. Scientific Reports, (September 2019), 110 .

Arnold, M., Sierra, M. S., Laversanne, M., Soerjomataram, I., Jemal, A., \& Bray, F. (2017). Global patterns and trends in colorectal cancer incidence and mortality. Gut, 66(4), 683-691. 
647 Bai, F. L., Yu, Y. H., Tian, H., Ren, G. P., Wang, H., Zhou, B., ... \& Li, D. S. (2014).

648 Genetically engineered Newcastle disease virus expressing interleukin-2 and TNF-related

649

650

651 apoptosis-inducing ligand for cancer therapy. Cancer Biology \& Therapy, 15(9), 1226-1238.

652

653

Bailey, K. L., Agarwal, E., Chowdhury, S., Luo, J., Brattain, M. G., Black, J. D., \& Wang, J. (2017). TGF $\beta /$ Smad3 regulates proliferation and apoptosis through IRS-1 inhibition in colon cancer cells. PLoS ONE, 12(4), 1-14.

654

655

Ben-Izhak, O., Laster, Z., Araidy, S., \& Nagler, R. M. (2007). TUNEL - An efficient prognosis

656

657

658

659

660

661

662

663

predictor of salivary malignancies. British Journal of Cancer, 96(7), 1101-1106.

Bian, H., Wilden, H., Fournier, P., Peeters, B., \& Schirrmacher, V. (2006). In vivo efficacy of systemic tumor targeting of a viral RNA vector with oncolytic properties using a bispecific adapter protein. International Journal of Oncology, 29(6), 1359-1369.

664

665

666

Boisgerault, N., Guillerme, J. B., Pouliquen, D., Mesel-Lemoine, M., Achard, C., Combredet, C., ... Grégoire, M. (2013). Natural oncolytic activity of live-attenuated measles virus against human lung and colorectal adenocarcinomas. BioMed Research International, 2013, 1-11.

667

668

669

670

671

Cardiff, R. D., Miller, C. H., \& Munn, R. J. (2014). Manual hematoxylin and eosin staining of mouse tissue sections. Cold Spring Harbor Protocols, 2014(6), 655-658.

Chauhan, P., Yadar, R., Kaushal, V., \& Beniwal, P. (2016). Evaluation of serum biochemical profile of breast cancer patients. European Journal of Pharmaceutical and Medical Research, $5(7), 1-7$.

672

673

Choi, I. K., Lee, J. S., Zhang, S. N., Park, J., Lee, K. M., Sonn, C. H., \& Yun, C. O. (2011).

674

675

676

677 Oncolytic adenovirus co-expressing IL-12 and IL-18 improves tumor-specific immunity via differentiation of T cells expressing IL-12RB2 or IL-18R $\alpha$. Gene Therapy, 18(9), 898-909.

678

679

680

Elmore, S. (2007). Apoptosis: A Review of Programmed Cell Death. Toxicologic Pathology, 35(4), 495-516.

681

Gang, W., Wang, J., Guan, R., Yan, S., Shi, F., Zhang, J., ... Fu, X. (2018). Strategy to targeting 6821603.

683

684

685

686

687

688

689

690

691

Gerber, S. A., Sedlacek, A. L., Cron, K. R., Murphy, S. P., Frelinger, J. G., \& Lord, E. M. (2013). IFN- $\gamma$ mediates the antitumor effects of radiation therapy in a murine colon tumor. American Journal of Pathology, 182(6), 2345-2354.

Goldufsky, J., Sivendran, S., Harcharik, S., Pan, M., Bernardo, S., Stern, R., ... Kaufman, H. (2013). Oncolytic virus therapy for cancer. Oncolytic Virotherapy, 2, 31-46.

692

Gong, J., Sachdev, E., Mita, A. C., \& Mita, M. M. (2016). Clinical development of reovirus for cancer therapy: An oncolytic virus with immune-mediated antitumor activity. World Journal of 
693

694

695

696

697

698

699

700

701

702

703

704

705

706

707

708

709

710

711

712

713

714

715

716

717

718

719

720

721

722

723

724

725

726

727

728

729

730

731

732

733

734

735

736

737

738

Methodology, 6(1), 25.

Granot, T., Venticinque, L., Tseng, J. C., \& Meruelo, D. (2011). Activation of cytotoxic and regulatory functions of NK cells by sindbis viral vectors. PLoS ONE, 6(6).

Guinney, J., Dienstmann, R., Wang, X., de Reynies, A., Schlicker, A., Soneson, C., ... Tejpar, S. (2016). The Consensus Molecular Subtypes of Colorectal Cancer. Nature Medicine, 21(11), $1350-1356$.

Jiang, K., Song, C., Kong, L., Hu, L., Lin, G., Ye, T., ... \& Barr, M. P. (2018). Recombinant oncolytic Newcastle disease virus displays antitumor activities in anaplastic thyroid cancer cells. BMC Cancer, 18(1), 746.

Jing, Y., Zaias, J., Duncan, R., Russell, S. J., \& Merchan, J. R. (2014). In vivo safety, biodistribution and antitumor effects of UPAR retargeted oncolytic measles virus in syngeneic cancer models. Gene Therapy, 21(3), 289-297.

Kalyanasundram, J., Hamid, A., Yusoff, K., \& Chia, S. L. (2018). Newcastle disease virus strain AF2240 as an oncolytic virus: A review. Acta Tropica, 183(February), 126-133.

Kang, S., Na, Y., Joung, S. Y., Lee, S. Il, Oh, S. C., \& Min, B. W. (2018). The significance of microsatellite instability in colorectal cancer after controlling for clinicopathological factors. Medicine, 97(9), 1-6.

Kantari, C., \& Walczak, H. (2011). Caspase-8 and Bid: Caught in the act between death receptors and mitochondria. Biochimica et Biophysica Acta - Molecular Cell Research, 1813(4), $558-563$.

Kelly, E., \& Russell, S. J. (2007). History of oncolytic viruses: Genesis to genetic engineering. Molecular Therapy, 15(4), 651-659.

Kersemans, V., Cornelissen, B., Allen, P. D., Beech, J. S., \& Smart, S. C. (2013). Subcutaneous tumor volume measurement in the awake, manually restrained mouse using MRI. Journal of Magnetic Resonance Imaging, 37(6), 1499-1504.

Kim, W. R., Flamm, S. L., Di Bisceglie, A. M., \& Bodenheimer, H. C. (2008). Serum activity of alanine aminotransferase (ALT) as an indicator of health and disease. Hepatology, 47(4), 13631370 .

Kocarnik, J. M., Shiovitz, S., \& Phipps, A. I. (2015). Molecular phenotypes of colorectal cancer and potential clinical applications. Gastroenterology Report, 3(4), 269-276.

Kojima, T., Watanabe, Y., Hashimoto, Y., Kuroda, S., Yamasaki, Y., Yano, S., .. Fujiwara, T. (2010). In vivo biological purging for lymph node metastasis of human colorectal cancer by telomerase-specific oncolytic virotherapy. Annals of Surgery, 251(6), 1079-1086. 
739 Koudelka, K. J., Pitek, A. S., Manchester, M., \& Steinmetz, N. F. (2015). Virus-Based

740

741

742

743

744

745

746

747

748

749

750

751

752

753

754

755

756

757

758

759

760

761

762

763

764

765

766

767

768

769

770

771

772

773

774

775

776

777

778

779

780

781

782

783

784

Nanoparticles as Versatile Nanomachines. Annu Rev Virol, 2(1), 379-401.

Lam, H. Y., Yeap, S. K., Rasoli, M., Omar, A. R., Yusoff, K., Suraini, A. A., \& Banu Alitheen, N. (2011). Safety and clinical usage of newcastle disease virus in cancer therapy. Journal of Biomedicine and Biotechnology, 2011.

Lasek, W., Zagożdżon, R., \& Jakobisiak, M. (2014). Interleukin 12: still a promising candidate for tumor immunotherapy? Cancer Immunology, Immunotherapy, 63(5), 419-435.

Lee, S., \& Margolin, K. (2011). Cytokines in cancer immunotherapy. Cancers, 3(4), 3856-3893.

Li, X. Y., Li, Z., An, G. J., Liu, S., \& Lai, Y. D. (2014). Co-expression of perforin and granzyme $\mathrm{B}$ genes induces apoptosis and inhibits the tumorigenicity of laryngeal cancer cell line Hep-2. International Journal of Clinical and Experimental Pathology, 7(3), 978-986.

Linnekamp, J. F., Wang, X., Medema, J. P., \& Vermeulen, L. (2015). Colorectal Cancer Heterogeneity and Targeted Therapy: A Case for Molecular Disease Subtypes. Cancer Research, 75(2), 245-250.

Merlano, M. C., Granetto, C., Fea, E., Ricci, V., \& Garrone, O. (2017). Heterogeneity of colon cancer : from bench to bedside. ESMO Open, 2, 1-8.

Mhaidat, N. M., Al-azzam, S. I., Alzoubi, K. H., Khabour, O. F., \& Gharaibeh, B. F. (2014). Granzyme B gene polymorphisms, colorectal cancer risk, and metastasis. Journal of Cancer Research and Therapeutics, 10(3), 587-590.

Mithani, S. K., Balch, G. C., Shiou, S. R., Whitehead, R. H., Datta, P. K., \& Beauchamp, R. D. (2004). Smad3 has a critical role in TGF- $\beta$-mediated growth inhibition and apoptosis in colonic epithelial cells. Journal of Surgical Research, 117(2), 296-305.

Murulitharan, K., Yusoff, K., Omar, A. R., \& Molouki, A. (2013). Characterization of Malaysian velogenic NDV strain AF2240-I genomic sequence: A comparative study. Virus Genes, 46(3), 431-440.

Pan, Y., Trojan, J., Guo, Y., \& Anthony, D. D. (2013). Rescue of MHC-1 Antigen Processing Machinery by Down-Regulation in Expression of IGF-1 in Human Glioblastoma Cells. PLoS ONE, 8(3), 1-11.

Parihar, R., Dierksheide, J., Hu, Y., \& Carson, W. E. (2002). IL-12 enhances the natural killer cell cytokine response to Ab-coated tumor cells. Journal of Clinical Investigation, 110(7), 983992.

Paul-Samojedny, M., Kokocińska, D., Samojedny, A., Mazurek, U., Partyka, R., Lorenz, Z., \& Wilczok, T. (2005). Expression of cell survival/death genes: Bcl-2 and Bax at the rate of colon cancer prognosis. Biochimica et Biophysica Acta - Molecular Basis of Disease, 1741(1-2), 2529.

Peer) reviewing PDF | (2020:04:47395:2:0:NEW 21 Jul 2020) 
785

786

787

788

789

790

791

792

793

794

795

796

797

798

799

800

801

802

803

804

805

806

807

808

809

810

811

812

813

814

815

816

817

818

819

820

821

822

823

824

825

826

827

828

829

830

Pawłowska, N., Gornowicz, A., Bielawska, A., Surażyński, A., Szymanowska, A., Czarnomysy, R., \& Bielawski, K. (2018). The molecular mechanism of anticancer action of novel octahydropyrazino[2,1-a:5,4-a']diisoquinoline derivatives in human gastric cancer cells. Investigational New Drugs, 36(6), 970-984.

Prizment, A., Vierkant, R., Smyrk, T., Tilmans, L., Nelson, H., Lynch, C., ... Limburg, P. (2017). Cytotoxic T-cells and granzyme B associated with improved colorectal cancer survival in a prospective cohort of older women. Cancer Epidermiol Biomarkers Prev, 26(4), 622-631.

Pryczynicz, A., Gryko, M., Niewiarowska, K., Cepowicz, D., Ustymowicz, M., Kemona, A., \& Guzińska-Ustymowicz, K. (2014). Bax protein may influence the invasion of colorectal cancer. World Journal of Gastroenterology, 20(5), 1305-1310.

Rausalova, I., \& Krepela, E. (2010). Granzyme B-induced apoptosis in cancer cells and its regulation (Review). International Journal of Oncology, 37, 1361-1378.

Riley, M. K., \& Vermerris, W. (2017). Recent advances in nanomaterials for gene delivery-A review. Nanomaterials, 7(5), 1-19.

Rozek, L. S., Schmit, S. L., Greenson, J. K., Tomsho, L. P., Rennert, H. S., Rennert, G., \& Gruber, S. B. (2016). Tumor-Infiltrating Lymphocytes , Crohn' s-Like Lymphoid Reaction, and Survival From Colorectal Cancer. JNCI Natl Cancer Inst, 108(8), 1-8.

Saif, M. W., Alexander, D., \& Wicox, C. M. (2005). Serum alkaline phosphatase level as a prognostic tool in colorectal cancer: A study of 105 patients. Journal of Applied Research, 5(1), 88-95.

Salama, P., Phillips, M., Platell, C., \& Iacopetta, B. (2011). Low expression of Granzyme B in colorectal cancer is associated with signs of early metastastic invasion. Histopathology, 59(2), 207-215.

Schirrmacher, V. (2017). Immunobiology of newcastle disease virus and its use for prophylactic vaccination in poultry and as adjuvant for therapeutic vaccination in cancer patients. International Journal of Molecular Sciences, 18(5). https://doi.org/10.3390/ijms18051103

Song, K. Y., Wong, J., Gonzalez, L., Sheng, G., Zamarin, D., \& Fong, Y. (2010). Antitumor efficacy of viral therapy using genetically engineered Newcastle disease virus (NDV(F33a)GFP) for peritoneally disseminated gastric cancer. J Mol Med (Berl), 88(6), 589-596.

Sträter, J., Herter, I., Merkel, G., Hinz, U., Weitz, J., \& Möller, P. (2010). Expression and prognostic significance of APAF-1, caspase-8 and caspase-9 in stage II/III colon carcinoma: Caspase- 8 and caspase-9 is associated with poor prognosis. International Journal of Cancer, 127(4), 873-880.

Sveen, A., Bruun, J., Eide, P. W., Eilertsen, I. A., Ramirez, L., Arjama, M., ... Lothe, R. A.

Peer] reviewing PDF | (2020:04:47395:2:0:NEW 21 Jul 2020) 
831 (2018). Colorectal Cancer Consensus Molecular Subtypes Translated to Preclinical Models 832 Uncover Potentially Targetable Cancer Cell Dependencies. Clinical Cancer Research, 24(4), $833794-807$.

834

835

Syed Najmuddin, S. U. F., Romli, M. F., Hamid, M., Alitheen, N. B., \& Abd Rahman, N. M. A.

836

837

838

839

840

841

842

843

844

845

846

847

848 N. (2016). Anti-cancer effect of Annona Muricata Linn Leaves Crude Extract (AMCE) on breast cancer cell line. BMC Complementary and Alternative Medicine, 16(1), 1-20.

Tsai, Y. J., Lin, J. K., Chen, W. S., Jiang, J. K., Teng, H. W., Yen, C. C., ... Yang, S. H. (2016). Adjuvant FOLFOX treatment for stage III colon cancer: how many cycles are enough?

SpringerPlus, 5(1), 3-9.

Tugues, S., Burkhard, S. H., Ohs, I., Vrohlings, M., Nussbaum, K., Vom Berg, J., ... Becher, B. (2015). New insights into IL-12-mediated tumor suppression. Cell Death and Differentiation, 22(2), 237-246.

Westphal, D., Dewson, G., Czabotar, P. E., \& Kluck, R. M. (2011). Molecular biology of Bax and Bak activation and action. Biochimica et Biophysica Acta-Molecular Cell Research, 1813(4), 521-531.

850

851

852

853

854

855

856

Wu, Y., He, J., An, Y., Wang, X., Liu, Y., Yan, S., ... \& Yin, J. (2016). Recombinant Newcastle disease virus (NDV/Anh-IL-2) expressing human IL-2 as a potential candidate for suppresses growth of hepatoma therapy. Journal of Pharmacological Sciences, 132(1), 24-30.

Xu, X., Sun, Q., Mei, Y., Liu, Y., \& Zhao, L. (2018). Newcastle disease virus co-expressing interleukin 7 and interleukin 15 modified tumor cells as a vaccine for cancer immunotherapy.

857

858

859 Cancer Science, 109(2), 279-288.

Yang, L., Liu, Y., Wang, M., Qian, Y., Dong, X., Gu, H., ... Hisamitsu, T. (2016). Quercetininduced apoptosis of HT-29 colon cancer cells via inhibition of the Akt-CSN6-Myc signaling

861

862

863

864 axis. Molecular Medicine Reports, 14(5), 4559-4566.

Yin, L., Zhao, C., Han, J., Li, Z., Zhen, Y., Xiao, R., ... Sun, Y. (2017). Antitumor effects of oncolytic herpes simplex virus type 2 against colorectal cancer in vitro and in vivo. Therapeutics

865

866

867

868

869

870 and Clinical Risk Management, 13, 117-130.

Yu, J., Drisko, J., \& Chen, Q. (2013). Inhibition of pancreatic cancer and potentiation of gemcitabine effects by the extract of Pao Pereira. Oncology reports, 30(1), 149-156.

871

872

873

874 Zakay-Rones, Z., Tayeb, S., \& Panet, A. (2015). Therapeutic potential of oncolytic Newcastle 875 disease virus a critical review. Oncolytic Virotherapy, (March), 49.

876 
877 Zamarin, D., \& Palese, P. (2012). Oncolytic Newcastle Disease Virus for cancer therapy: old 878 challenges and new directions Dmitriy, 7(3), 347-367.

879

880 Zhang, L., Steele, M. B., Jenks, N., Grell, J., Behrens, M., Nace, R., ... \& Peng, K. W. (2016).

881 Robust oncolytic virotherapy induces tumor lysis syndrome and associated toxicities in the

882 MPC-11 plasmacytoma model. Molecular Therapy, 24(12), 2109-2117.

883 Zhao, B., Wang, L., Qiu, H., Zhang, M., Sun, L., \& Peng, P. (2017). Mechanisms of resistance to 884 anti-EGFR therapy in colorectal cancer. Oncotarget, 8(3), 3980-4000.

885 


\section{Figure 1}

Growth kinetics curve of AF2240-i and rAF-IL12 based on the viral copy number of these viruses detected in HT29 cells at 24,48 , and $72 \mathrm{~h}$ post-infection as measured by RTqPCR analysis.

Growth kinetics curve of AF2240-i and rAF-IL12 based on the viral copy number of these viruses detected in HT29 cells at 24,48 , and $72 \mathrm{~h}$ post-infection as measured by RT-qPCR analysis. The copy number was calculated based on the formula generated from the qPCR standard curve of the NDV: $X=(y-58.149) /-3.371$; where $X$ is the viral copy number; $y$ is the value mean $\mathrm{Cq} ; 58.149$ is the $y$-intercept value; and -3.371 is the slope of the standard curve. Data are presented as mean \pm S.E.M from triplicate determinations. Statistically significant differences between the means were determined by One-Way ANOVA followed by Duncan post hoc test. Differences were considered significant when the ${ }^{*} p \leq 0.05$ 


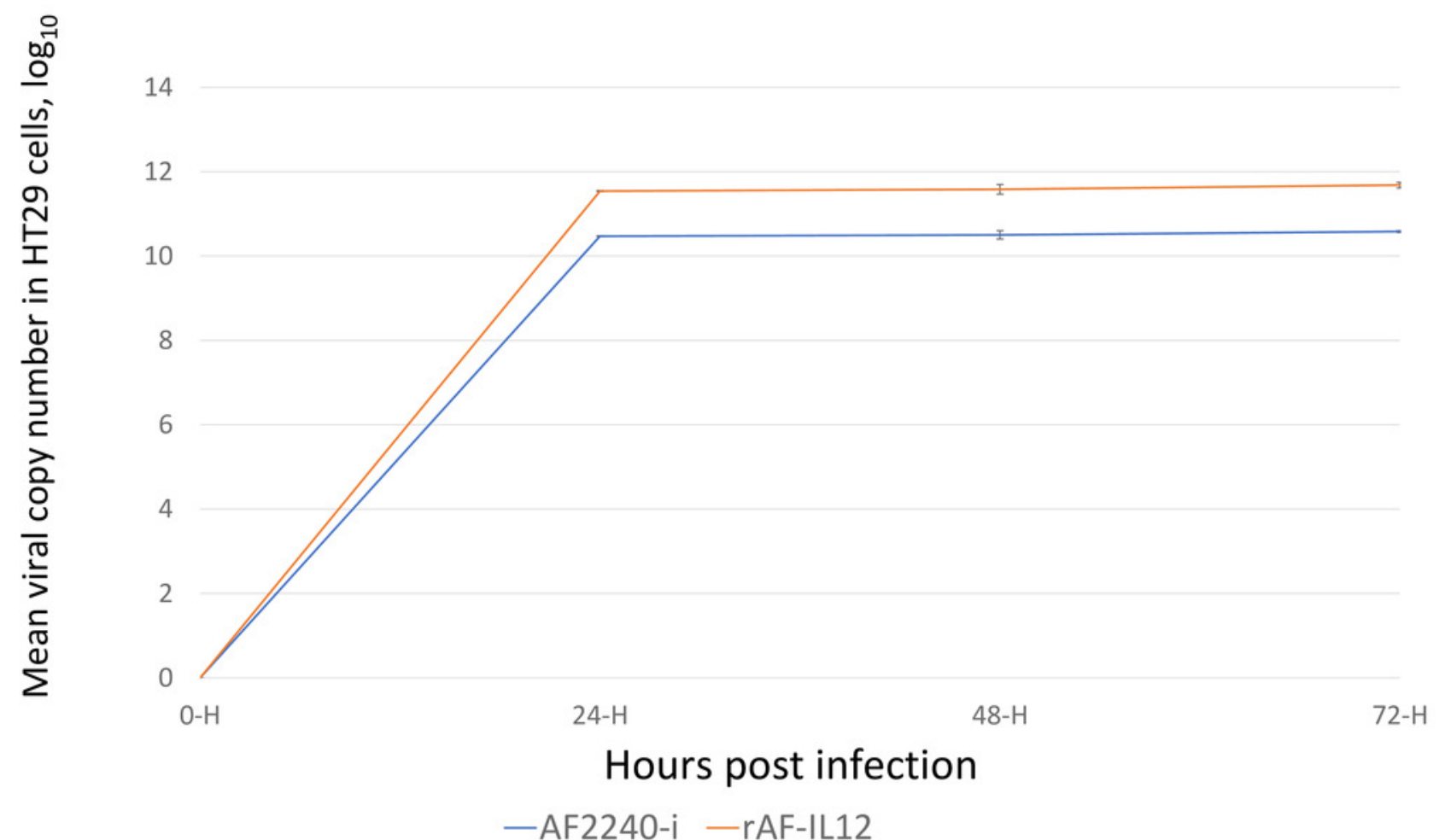


Figure 2

MTT assay showing the cytotoxicity activity of AF2240-i and RAF-IL12 against HT29 and 3T3 cells 72-h post-infection.

MTT assay showing the cytotoxicity activity of AF2240-i and rAF-IL12 against HT29 and 3T3 cells 72-h post-infection. Percentage of viability of two cell lines (HT29 and 3T3) when treated with seven doses of virus treatment (AF2240-i or rAF-IL12) after $72 \mathrm{~h}$. The $\mathrm{EC}_{50}$ value (half-maximal inhibitory concentration, HA unit) for AF2240-i-HT29=128 \pm 1.16 ; rAFIL12-HT29= 110 $\pm 0.58 ;$ AF2240-i-3T3= n.d.; rAF-IL12-3T3= n.d. Data are presented as mean \pm S.E.M from triplicate determinations.

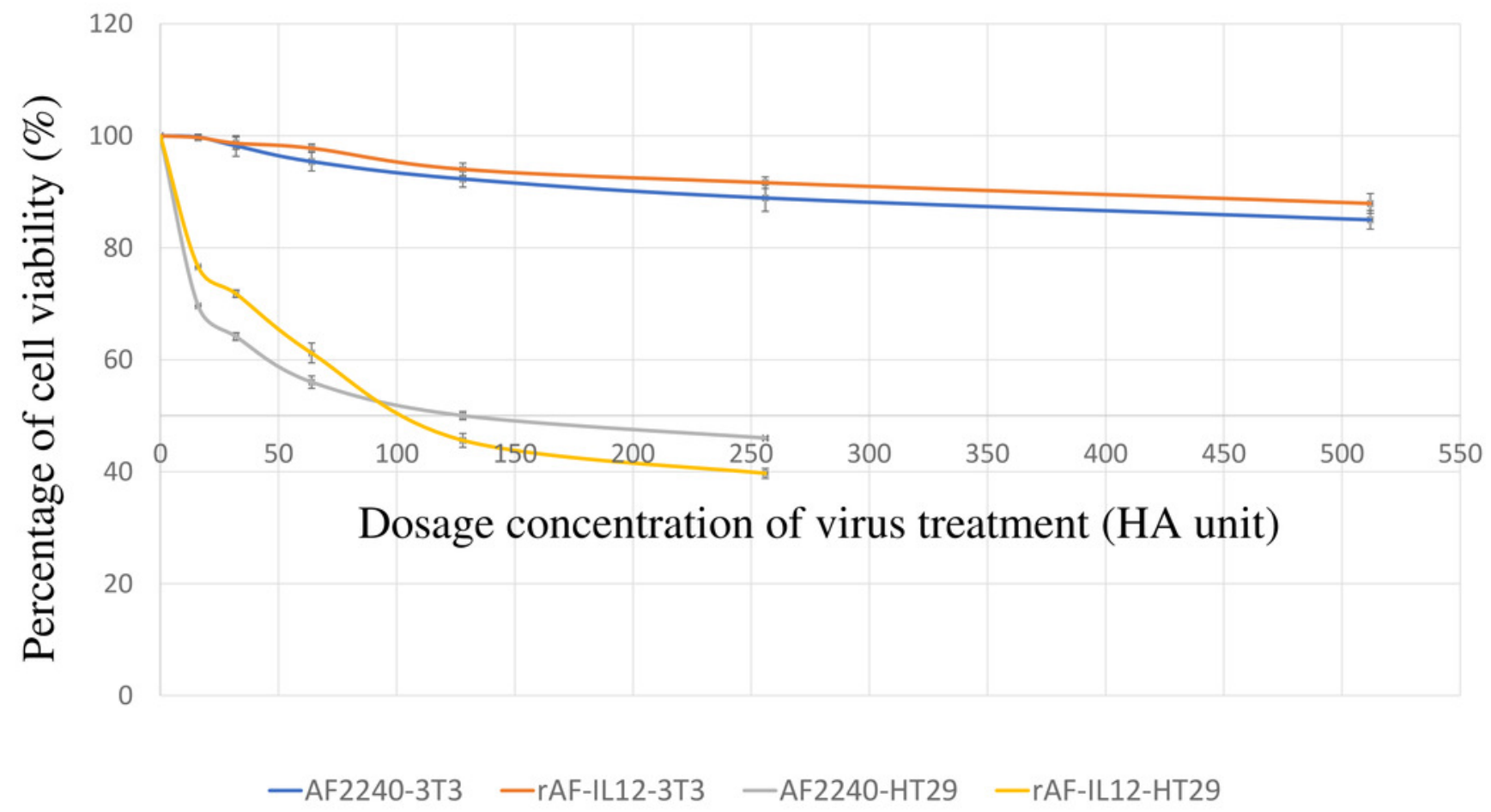




\section{Figure 3}

Annexin V/FITC assay in HT29 cells following AF2240-i (128 HA titre) and rAF-IL12 (110 HA titre) $72 \mathrm{~h}$ post-infection.

\section{Annexin V/FITC assay in HT29 cells following AF2240-i (128 HA titre) and rAF-IL12}

(110 HA titre) 72 h post-infection. (A-C) Typical quadrant analysis of Annexin V/FITC flow cytometry of HT29 cells apoptosis. The lower left quadrant of each group indicated the viable cells population; the lower right quadrant indicated the early apoptotic cells population; the upper right quadrant indicated the late apoptotic cells population; and the upper left quadrant indicated the necrotic cells population. Two fluorescent dyes were used in this assay which are FITC (x-axis) and PE (y-axis). (D) Percentage of viable, early apoptotic, and late apoptotic cells population analysed by quantitative analysis. Data are presented as mean \pm S.E.M from triplicate determinations. Mean values with statistical difference at $p<$ 0.05 between control, AF2240-i, and rAF-IL12 are indicated with *. 


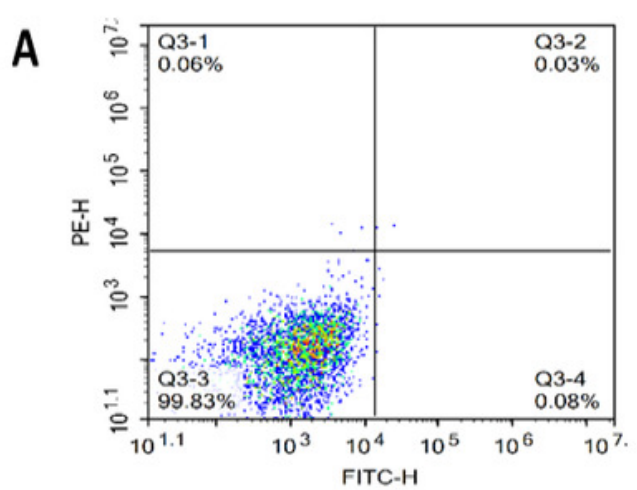

Negative Control

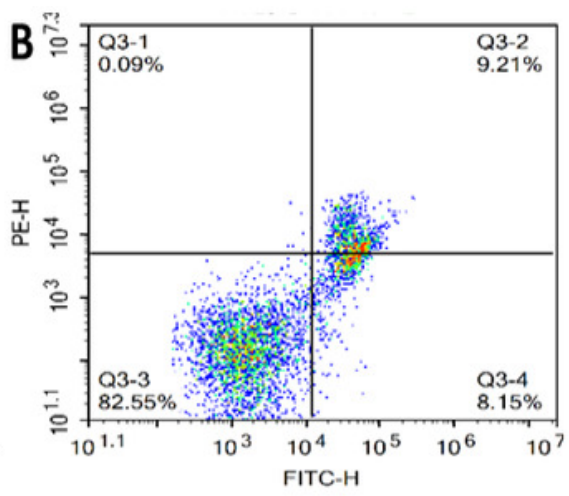

AF2240-i

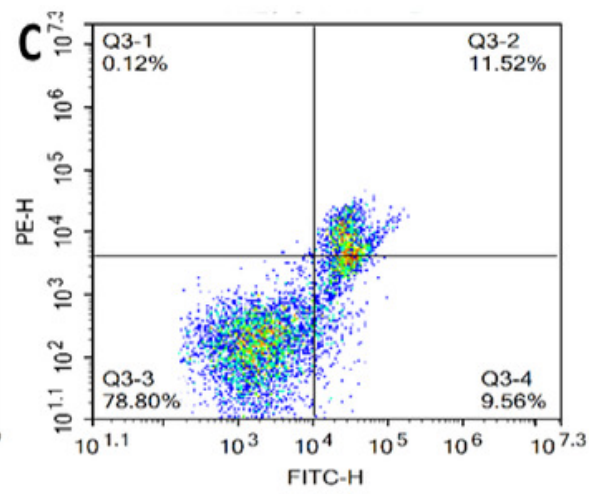

rAF-IL12

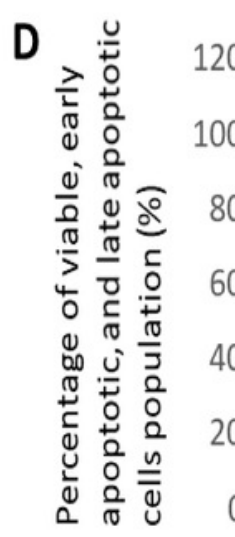

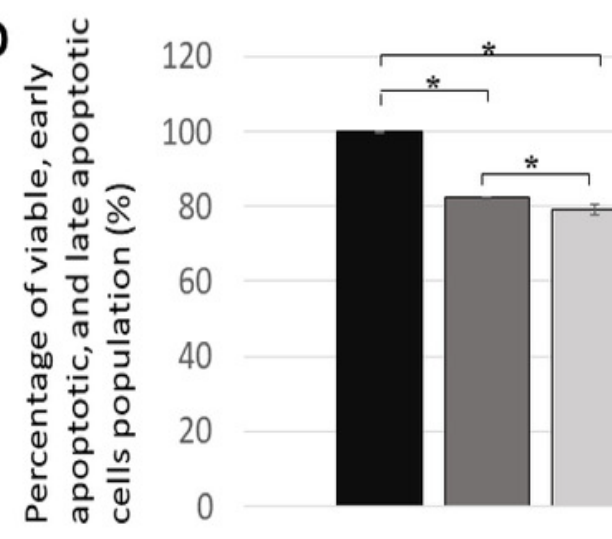

Viable

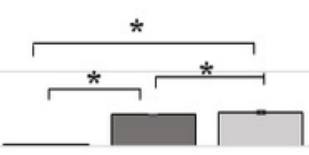

Early apoptotic

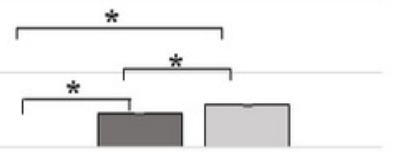

Late apoptotic

Negative Control $\quad$ AF2240-i $\quad$ rAF-IL12 


\section{Figure 4}

Cell cycle analysis of HT29 cells at different cell cycle phase.

Cell cycle analysis of HT29 cells at different cell cycle phase. (A-C) Histogram of cell cycle analysis showing distribution of $H T 29$ cells at different cell cycle phase $\left(G_{0}, G_{1}, S\right.$, and $\mathrm{G}_{2}$ ) after $72 \mathrm{~h}$ period of treatment with AF2240-i and rAF-IL12. The $\mathrm{G}_{0}$ peak appeared first in the histogram followed by $G_{1}, S$, and $G_{2}$ peaks indicating the percentage of cells population in those aforementioned cell cycle phases. Percentage of cells population in each peak was calculated from a total number of 10,000 cells in each flow cytometry run. (D) Percentage of cells population at different cell cycle phase analysed by flow cytometer following treatment with AF2240-i (128 HA titre) and rAF-IL12 (110 HA titre) in HT29 cells. Data are presented as mean \pm S.E.M from triplicate determinations. Mean values with statistical difference at $p<$ 0.05 between control, AF2240-i, and rAF-IL12 are indicated with * 

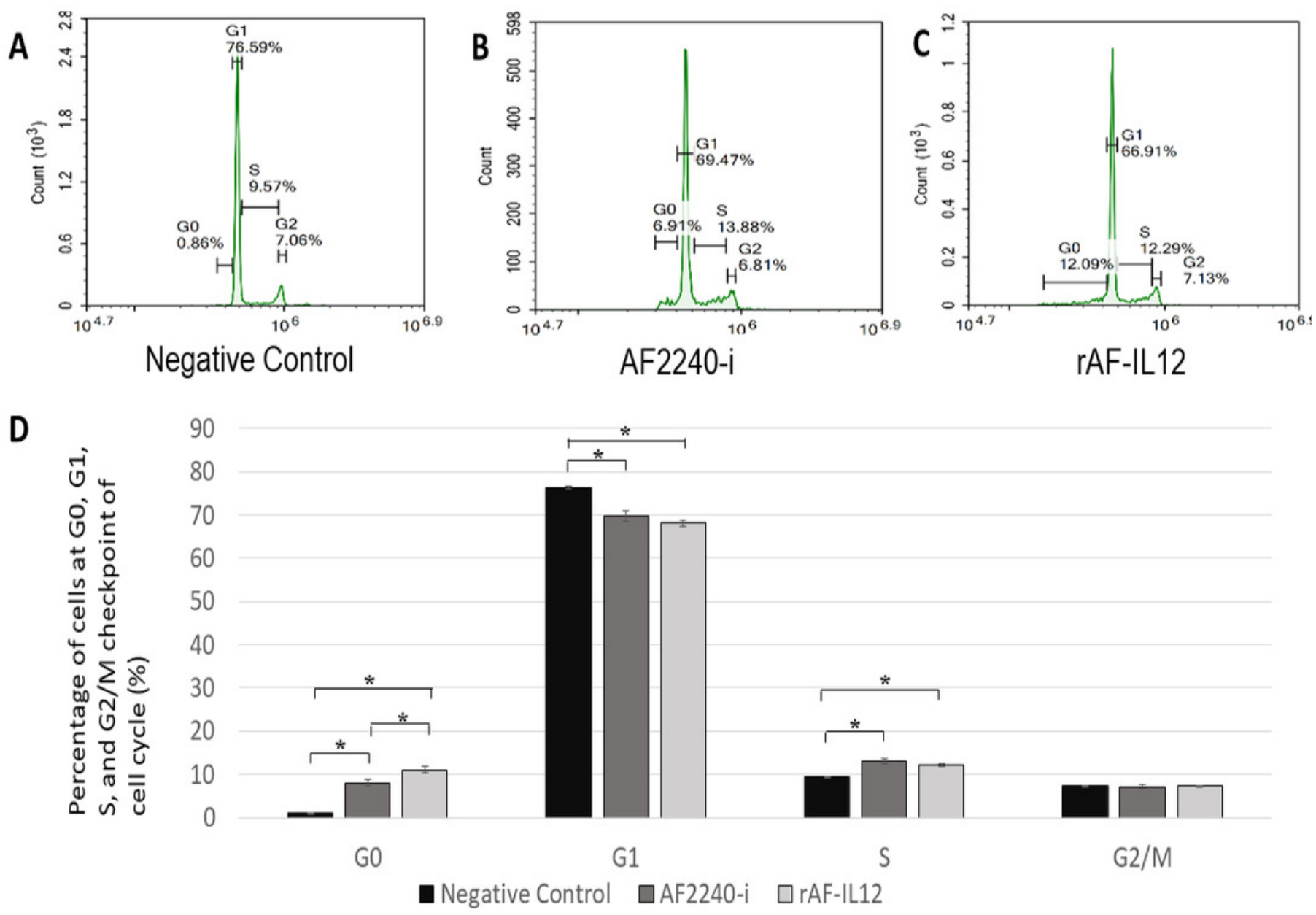


\section{Figure 5}

Effects on the HT29 tumours for the negative control, AF2240-i, and rAF-IL12 groups.

\section{Effects on the HT29 tumours for the negative control, AF2240-i, and rAF-IL12}

groups. (A) Images of HT29 tumour harvested from negative control, AF2240-i, and rAF-IL12 groups following the 28-days of treatment. (B) The growth rate of the HT29 tumours from day-0 until day-28 of treatments. (C) Average weight of HT29 tumours harvested from mice after 28-days of treatment. Data are represented as mean \pm S.E.M. Mean values with statistical difference at $p<0.05$ between control, AF2240-i, and rAF-IL12 are indicated with *.

A

Negative Control

AF2240-i

rAF-IL12

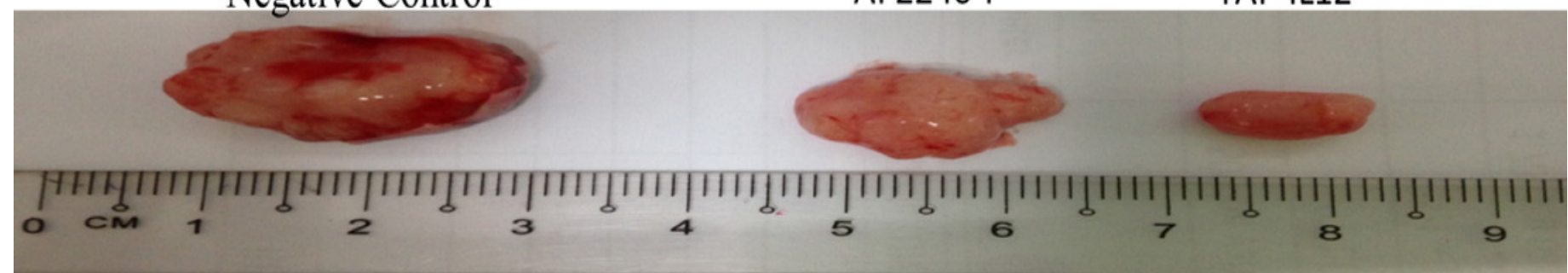

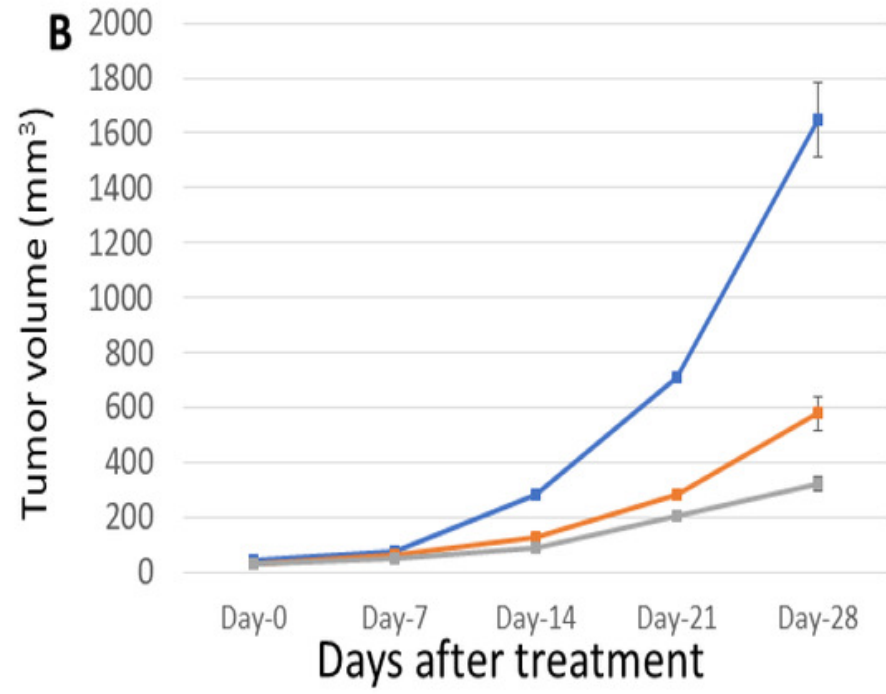

$=-$ Negative Control $\rightarrow$ AF2240-i $=$-rAF-IL12

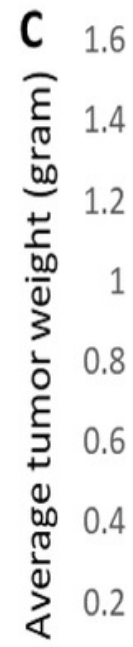

0

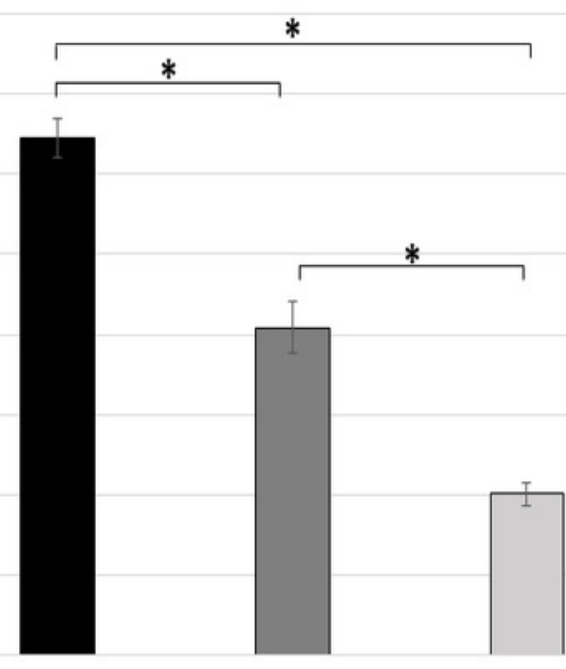

rAF-IL12 


\section{Figure 6}

Viral copy number inside the tumour, lung, and spleen (at day-28) of the AF2240-itreated and rAF-IL12-treated groups of the HT29 colon cancer-challenged mice study as determined by real-time PCR analysis.

Viral copy number inside the tumour, lung, and spleen (at day-28) of the AF2240-itreated and rAF-IL12-treated groups of the HT29 colon cancer-challenged mice study as determined by real-time PCR analysis. Data are presented as mean \pm S.E.M from triplicate determinations. Statistically significant differences between the means were determined by One-Way ANOVA followed by Duncan post hoc test. Differences were considered significant when the $* p \leq 0.05$.

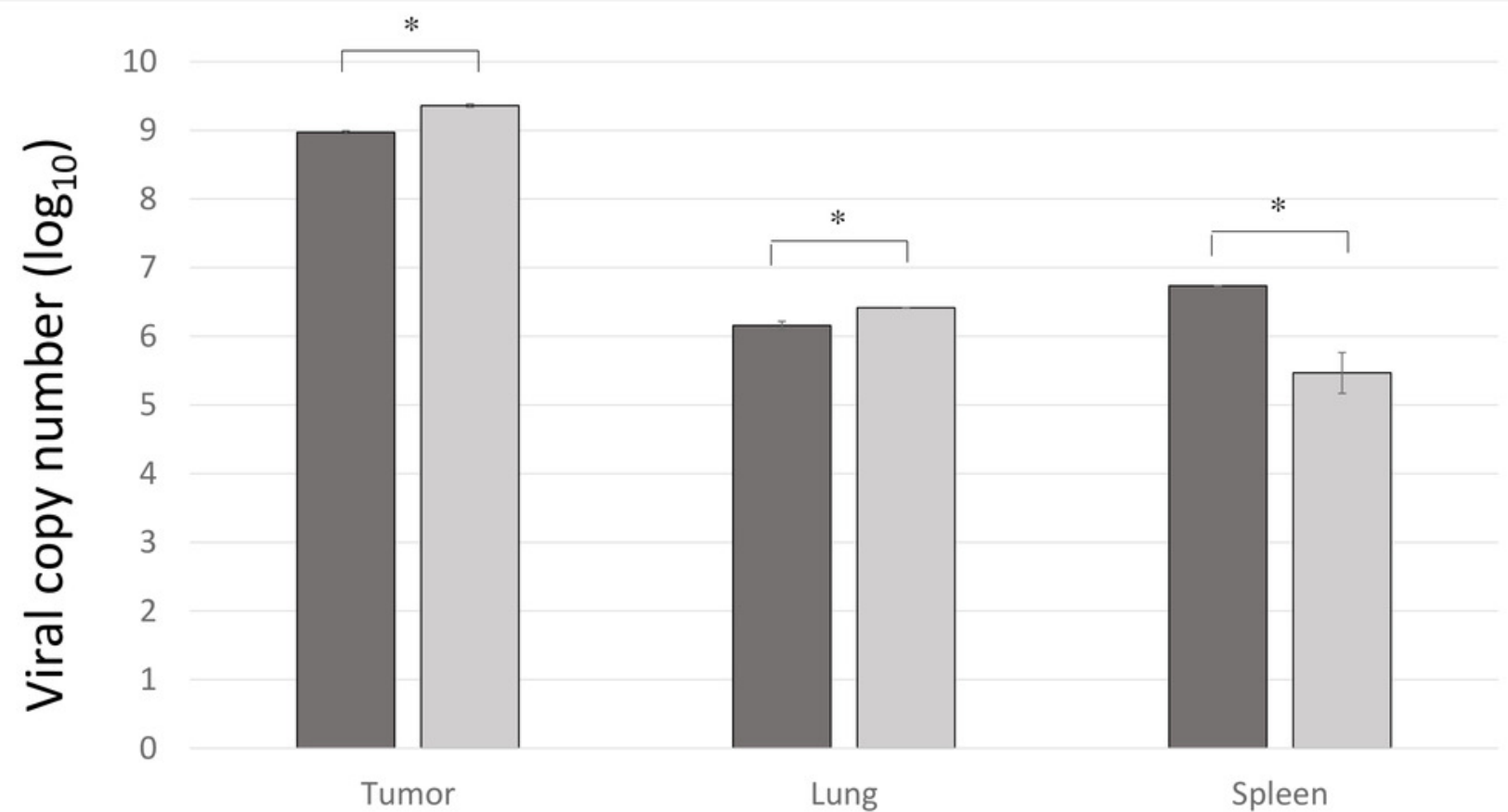




\section{Figure 7}

Photomicrograph section of nude mouse lung stained in H\&E.

\section{Photomicrograph section of nude mouse lung stained in H\&E; (A) Normal, (B)}

Untreated, (C) AF2240-i-treated, and (D) rAF-IL12-treated. Normal, untreated and rAF-IL12-treated groups showed normal alveolar morphology; alveolar air space (green arrow) and alveolar capillary (yellow arrow). AF2240-i treated group showed normal alveolar morphology; alveolar air space (green arrow) and alveolar capillary (yellow arrow) but with mild thickening of the alveolar interstitial wall due to leucocytic infiltration (blue arrow). Magnification: 100X; H\&E scale bar $=200 \mu \mathrm{m}$

\section{LUNG}

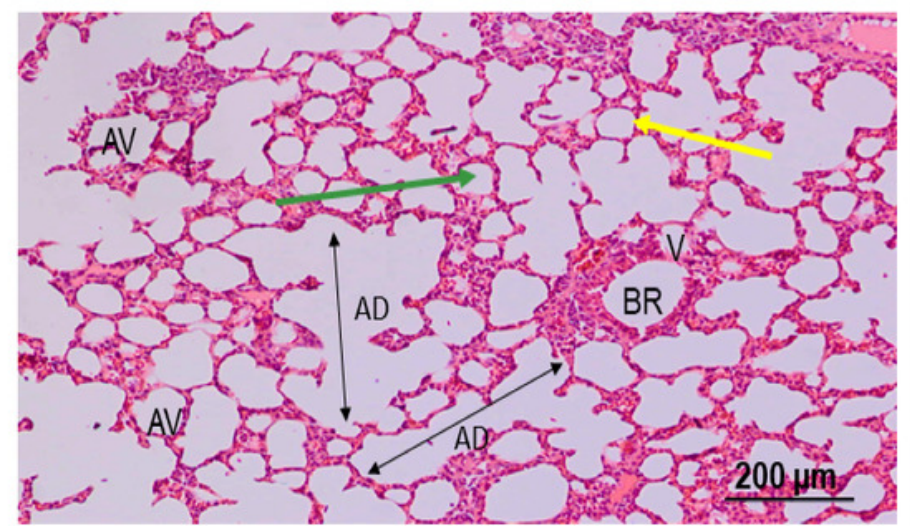

(A) Normal

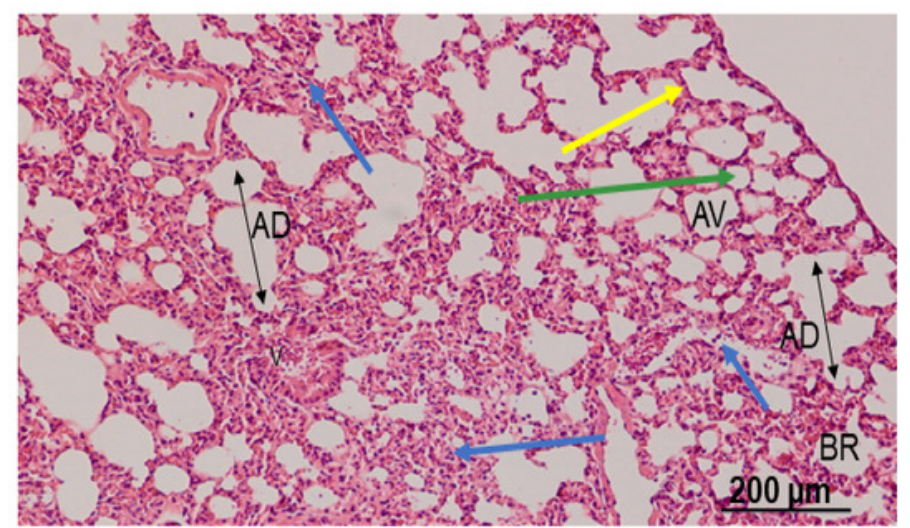

(C)AF2240-i

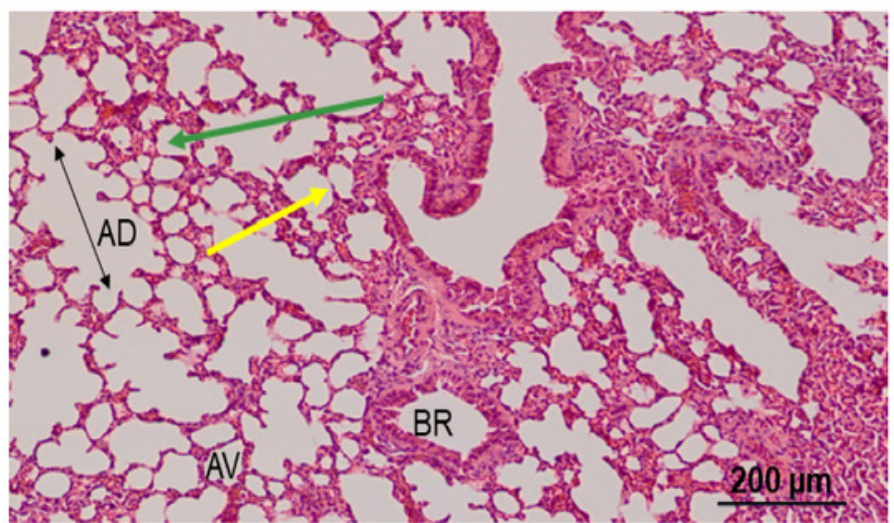

(B) Negative control/Untreated

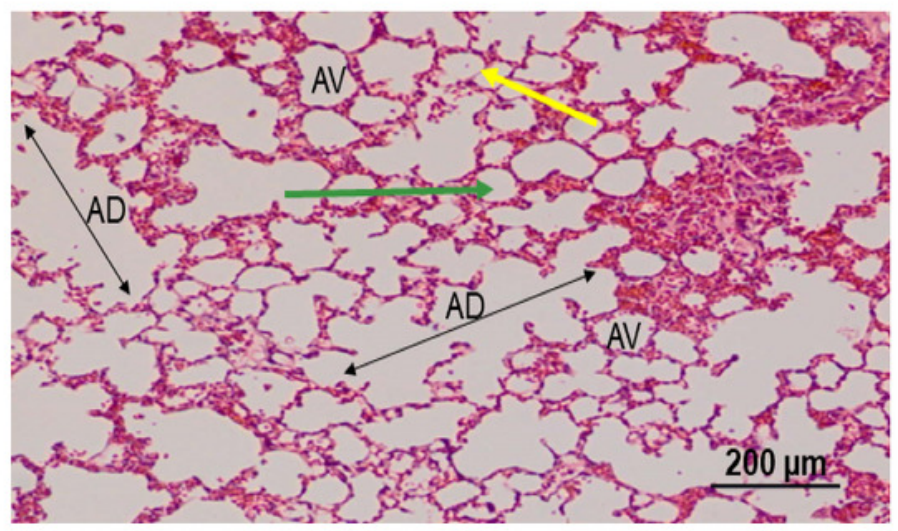

(D) rAF-IL12 


\section{Figure 8}

Photomicrograph of the spleen of nude mice stained in $\mathrm{H} \& \mathrm{E}$;

Photomicrograph of the spleen of nude mice stained in H\&E; (A) Normal, (B)

Untreated, (C) AF2240-i-treated, and (D) rAF-IL12-treated. Spleen from normal, AF2240-i, and rAF-IL12 groups showed no pathological changes with distinct white pulp and red pulp structure. Note lymphocyte depletion (yellow arrow) in the white pulp and poor distinction of the white pulp from the red pulp in the untreated group. WP, white pulp; RP, red pulp; CA, central artery; GC, germinal centre; PALS, periarteriolar lymphoid sheaths.

Magnification: 100x; H\&E scale bar $=200 \mu \mathrm{m}$

\section{SPLEEN}

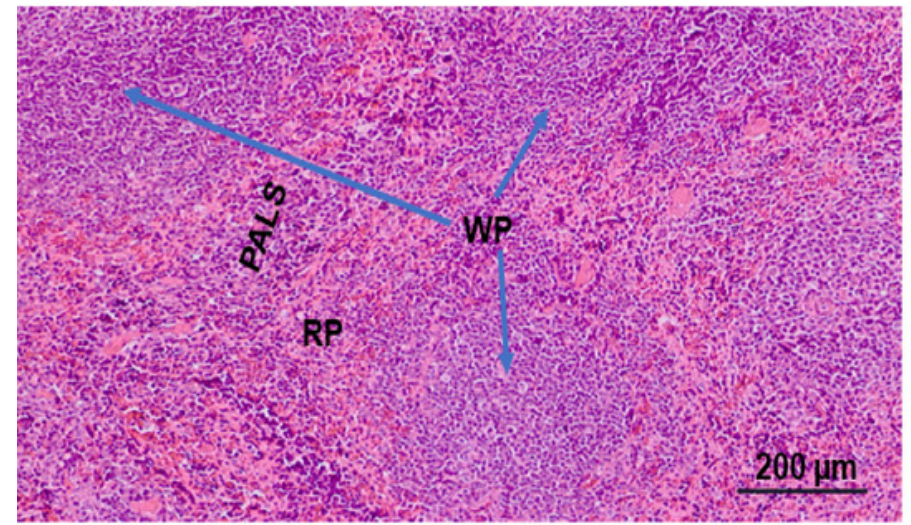

(A) Normal

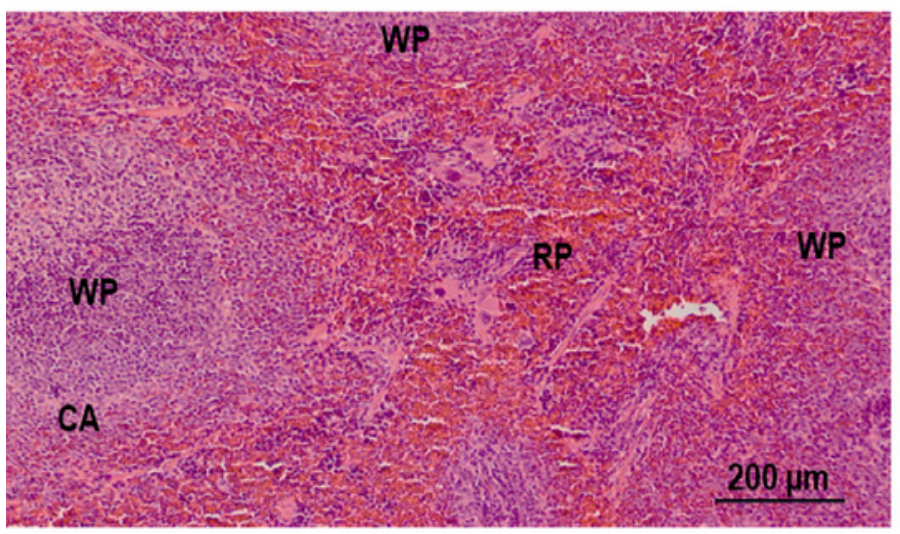

(C) AF2240-i

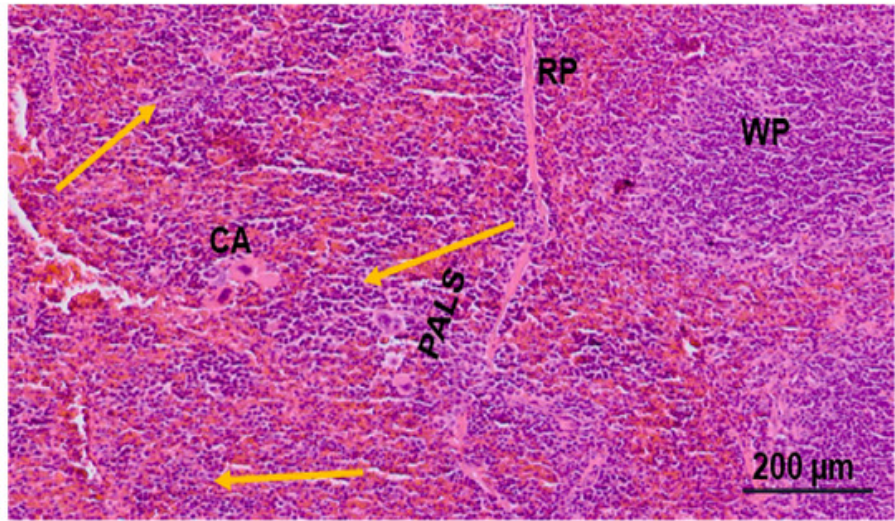

(B) Negative control/Untreated

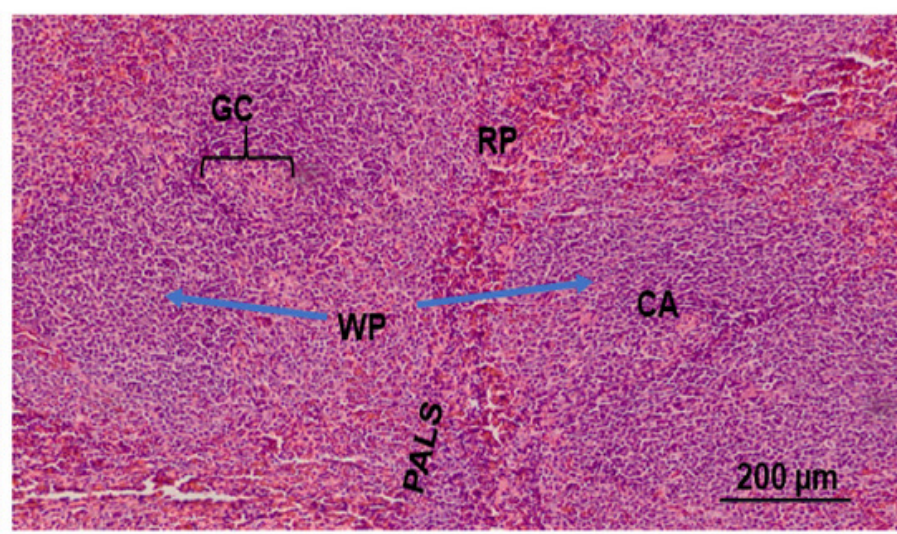

(D) rAF-IL12 


\section{Figure 9}

Photomicrograph section of nude mouse kidney stained with $\mathrm{H} \& \mathrm{E}$;

Photomicrograph section of nude mouse kidney stained with H\&E; (A) Normal, (B)

Untreated, (C) AF2240-i-treated, and (D) rAF-IL12-treated. Note leucocytic infiltration in the interstitial space (black arrow) in untreated and AF2240-i and the size of Bowman's space became smaller in the untreated group. RC, renal corpuscle with glomeruli; BS, Bowman's space; BC, Bowman's capsule; p, proximal tubule; d, distal tubule. Magnification: 400X; H\&E scale bar $=50 \mu \mathrm{m}$

\section{KIDNEY}

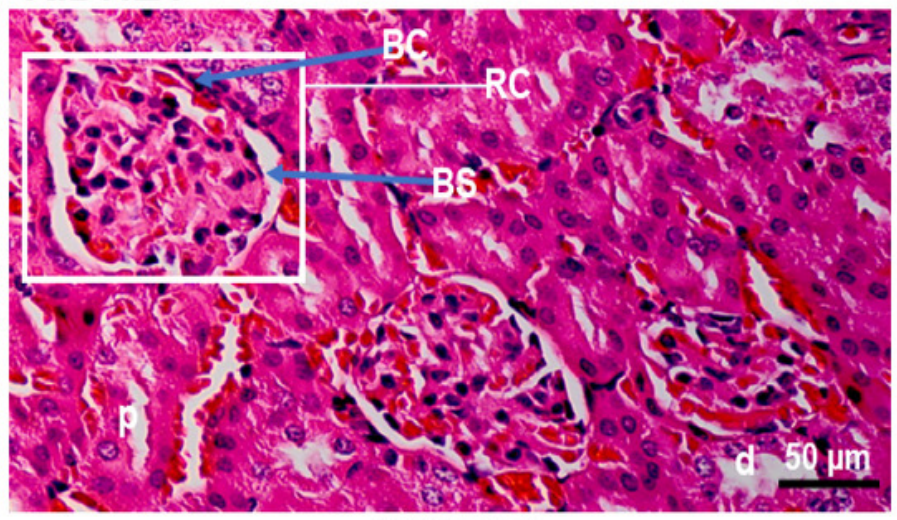

(A) Normal

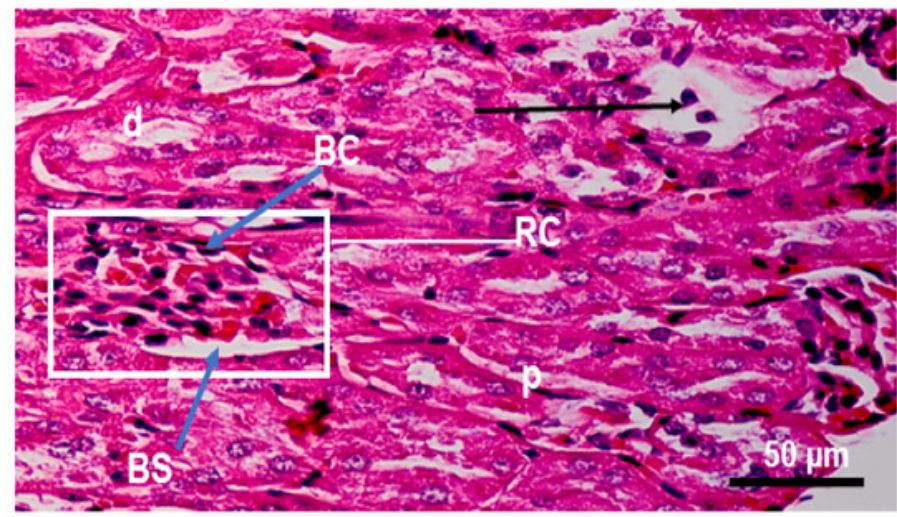

(C) AF2240-i

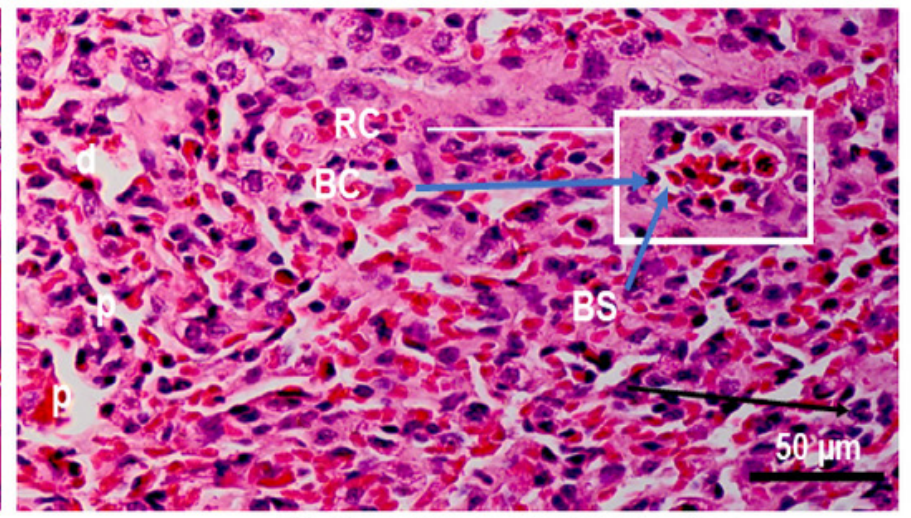

(B) Negative control/Untreated

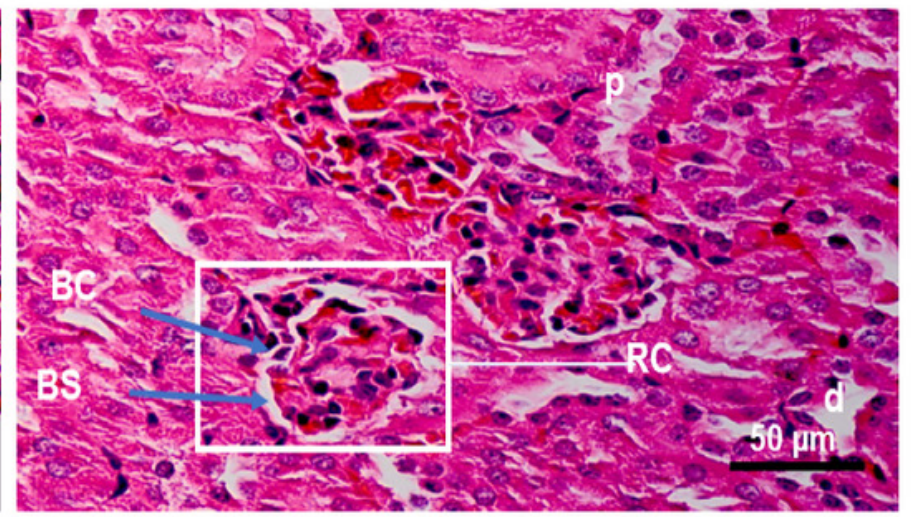

(D) rAF-IL12 


\section{Figure 10}

Photomicrograph of nude mouse liver stained in $H \& E$;

\section{Photomicrograph of nude mouse liver stained in H\&E; (A) Normal, (B) Untreated,}

(C) AF 2240-i-treated, and (D) rAF-IL12-treated. Normal hepatocytes with obvious

central vein shown in the normal group and rAF-IL12-treated group. Note the liver metastasis

(yellow arrow) and inflammatory infiltrates (green arrow) in the untreated and AF2240-i

groups. S, blood sinusoids; CV, central vein. Magnification: 400X; H\&E scale bar $=50 \mu \mathrm{m}$

\section{LIVER}

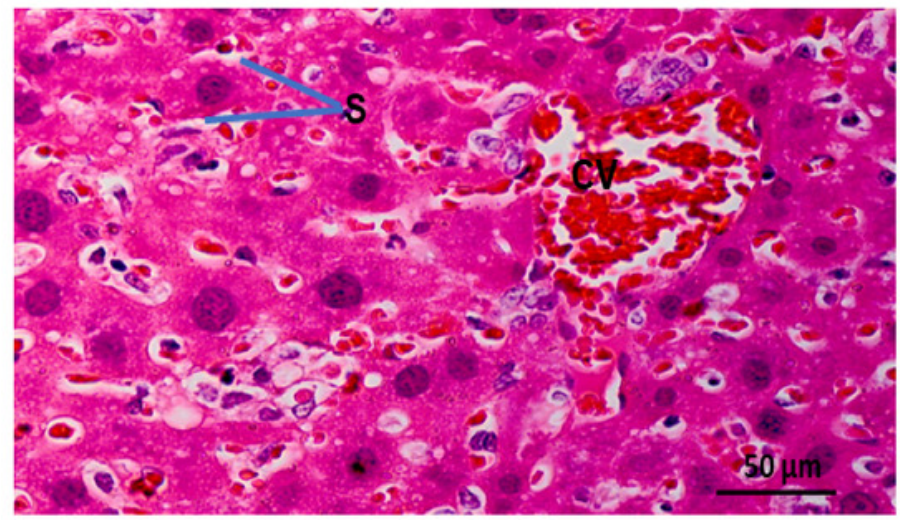

(A) Normal

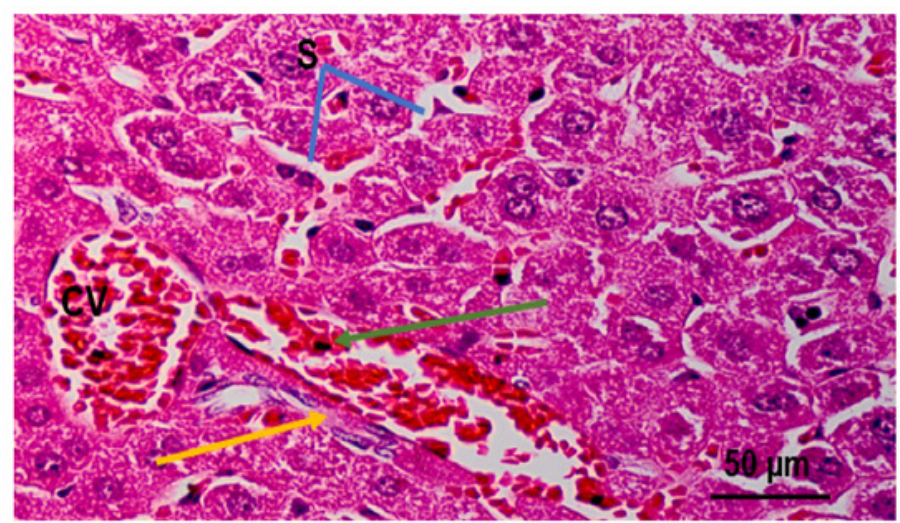

(C) AF2240-i

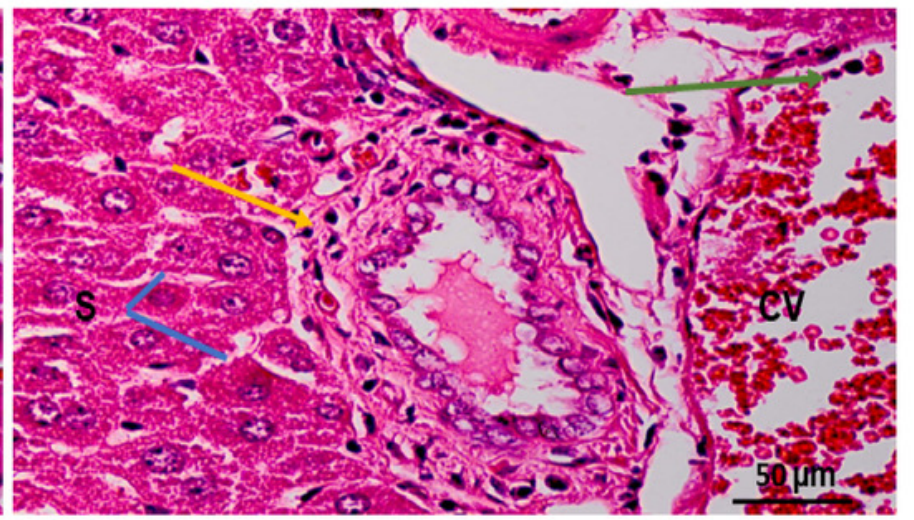

(B) Negative control/Untreated

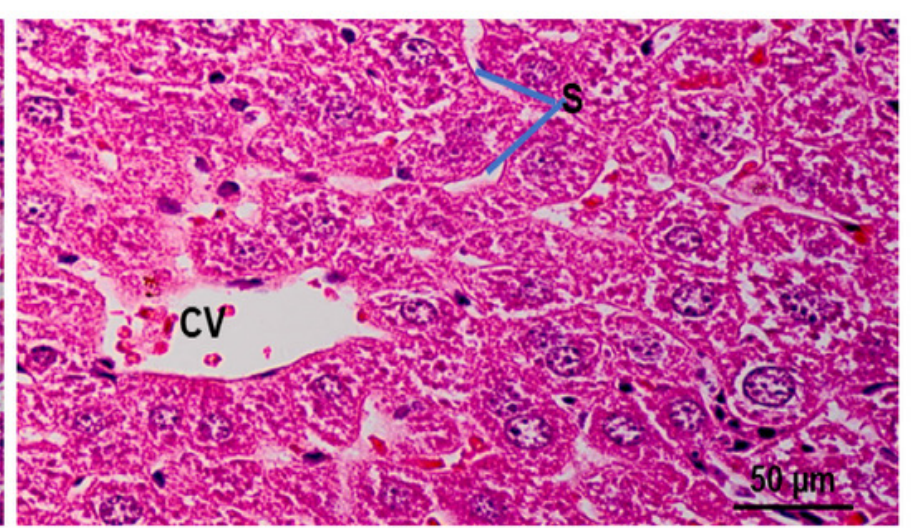

(D) rAF-IL12 
Figure 11

Serum level of cytokine

Serum level of cytokine (A) interleukin-12, (B) interleukin-2, and (C) interferon-Y from normal and colon cancer-challenged mice (negative control, AF2240-i, and rAF-IL12) after 28-days of treatment. Data are presented as mean \pm S.E.M. of triplicate determinations. Mean values with statistical difference at $p \leq 0.05$ between groups are indicated with *.

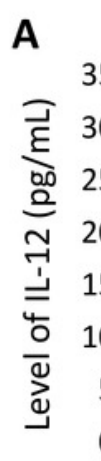

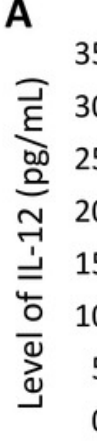

Normal Negative control AF2240-i

C

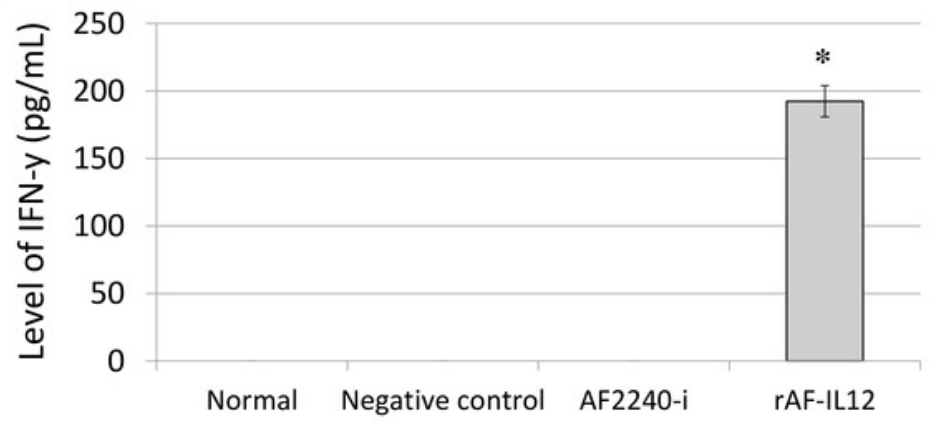

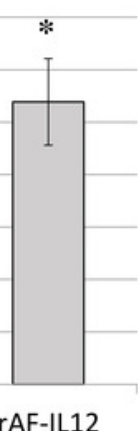

rAF-IL12

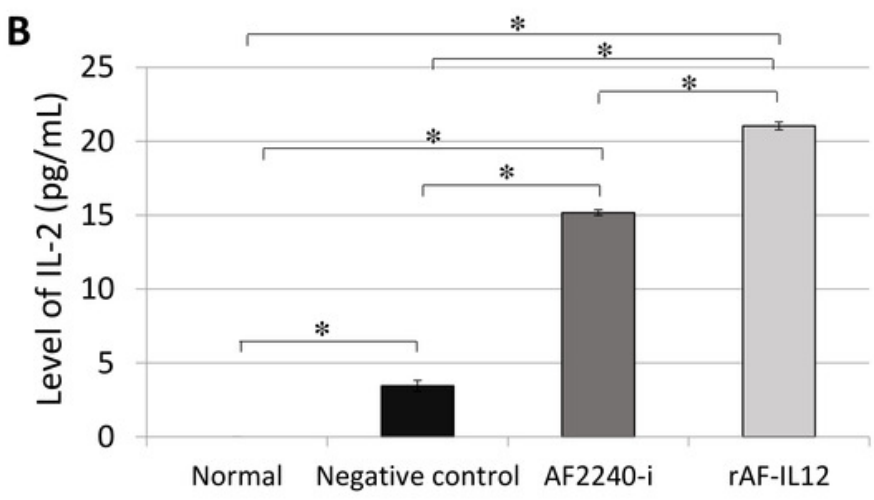

B 


\section{Figure 12}

Normalized gene expression level of Fas, caspase-8, BID, BAX, and SMAD3.

Normalized gene expression level of Fas, caspase-8, BID, BAX, and SMAD3 in (A) HT29 cancer cells in vitro and (B) tumour excised from HT29 tumour-burden mice (note the addition of granzyme B expression). Data are presented as mean \pm S.E.M from three independent experiments. Statistically significant differences between the means were determined by One-Way ANOVA followed by Duncan post hoc test. Differences were considered significant when the $p \leq 0.05$ as indicated by *

A
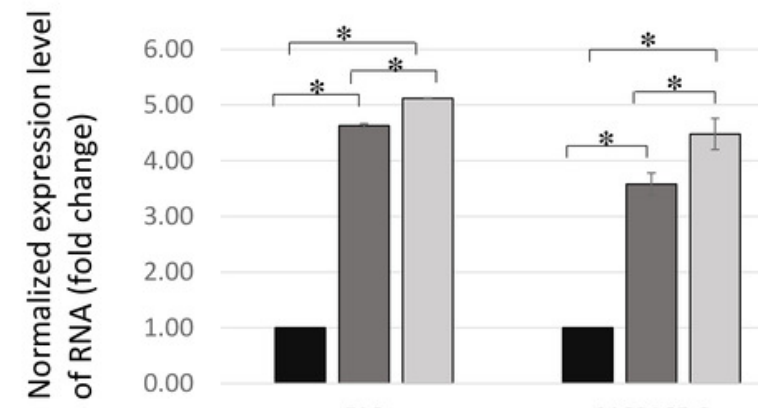

CASPASE-8

- Negative control

$\square$ AF2240-i

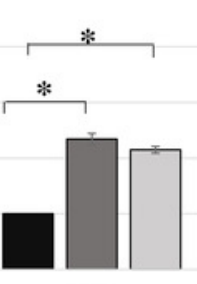

BID

口 rAF-IL12

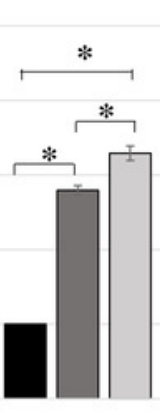

BID

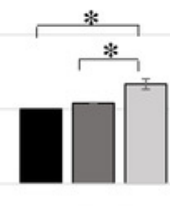

- Negative control
BAX

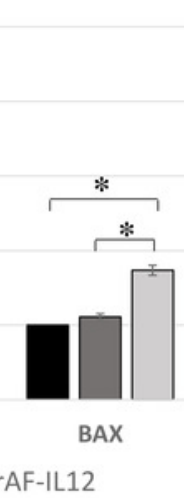

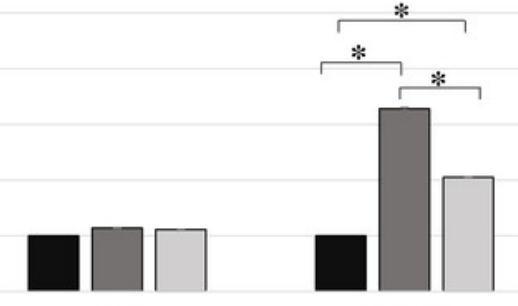

BAX

B

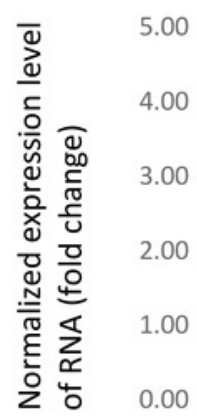

FAS

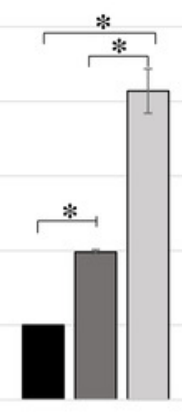

SMAD3

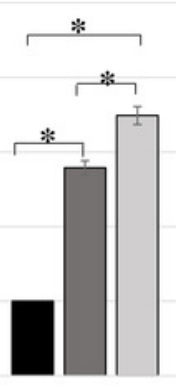

GRANZYME B 


\section{Figure 13}

Tumour sections assayed by DeadEnd colorimetric TUNEL system to indicate cell apoptosis in four different groups of HT29 tumour-bearing Balb/c mice.

(A-D) Tumour sections assayed by DeadEnd colorimetric TUNEL system to indicate cell apoptosis in four different groups of HT29 tumour-bearing Balb/c mice; positive control (sample treated with DNAse I), negative control, tumour treated with AF2240-i, and tumour treated with rAF-IL12. Brown stained nuclei in the black circle indicate DNA fragmentation and nuclear condensation. Magnification: 100x; (E) The number of apoptotic cells per tumour section from the four aforementioned groups after $\mathbf{2 8}$ days of treatment. Data are presented as mean \pm S.E.M. of triplicate determinations. Mean values with statistical difference at $p \leq 0.05$ between groups are indicated with* 


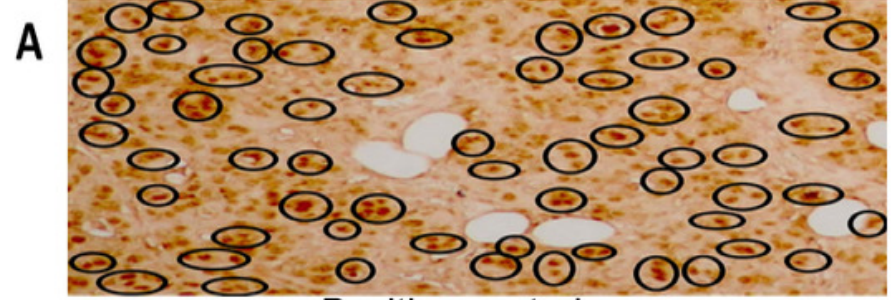

Positive control

c

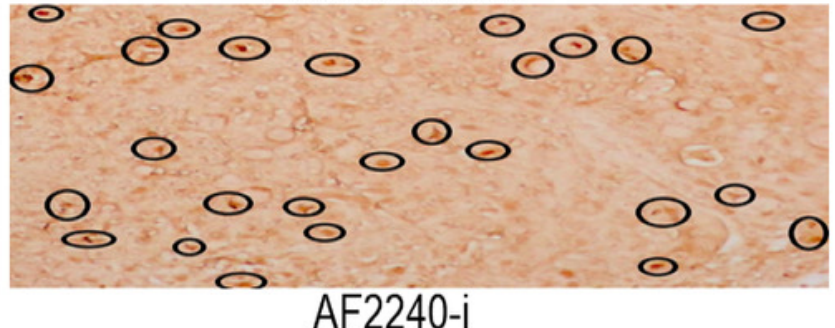

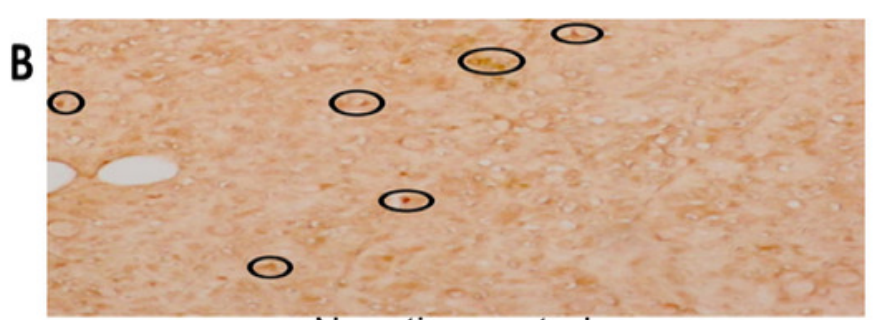

Negative control

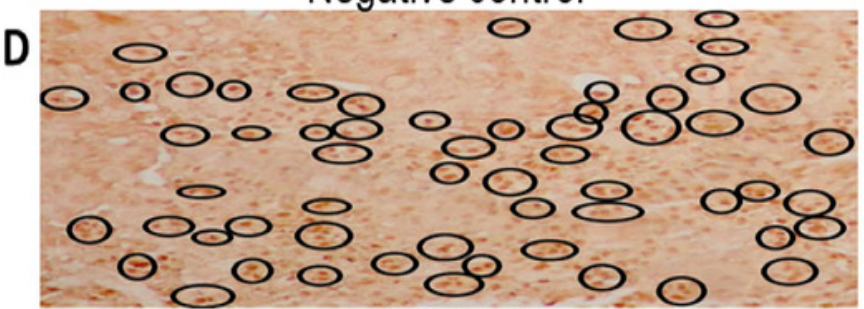

rAF-IL12

E

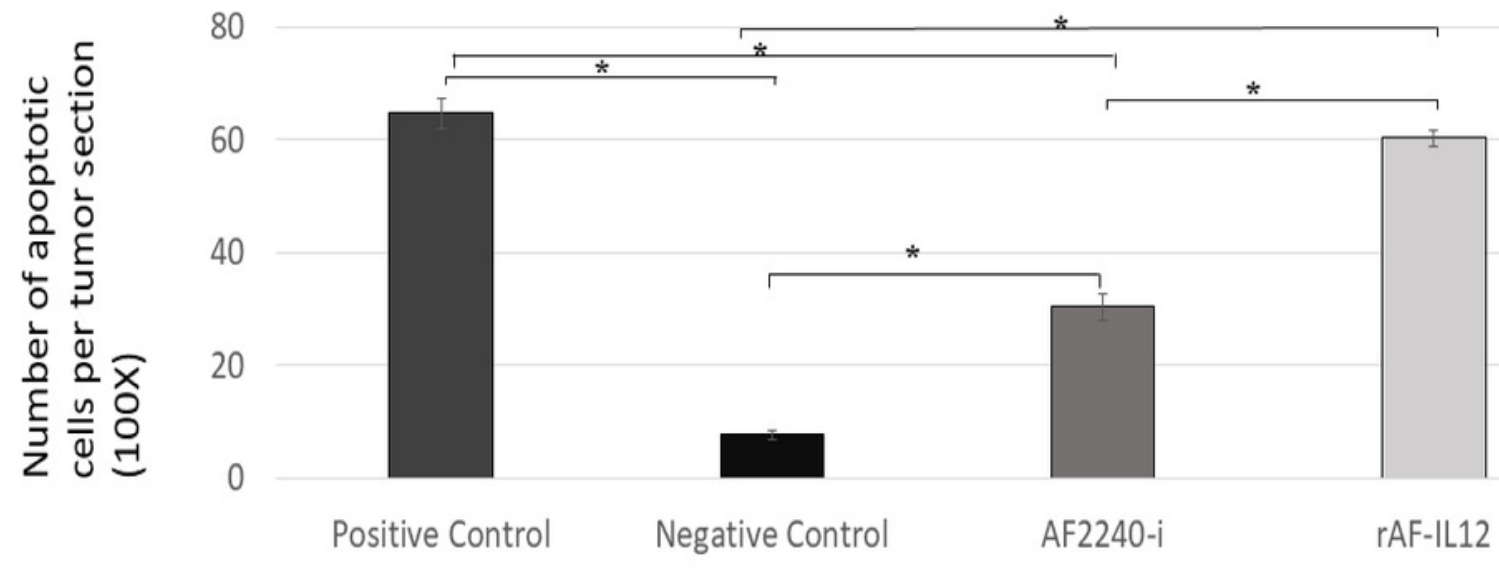




\section{Figure 14}

Photomicrograph section of the tumour mass of mice stained with $H \& E$ from three different groups of mice.

(A-C) Photomicrograph section of the tumour mass of mice stained with H\&E from three different groups of mice, negative control/untreated, AF2240-i-treated, and rAF-IL12-treated. The white circles indicate the actively dividing/mitotic tumour cells in the aforementioned groups. Magnification: 400X; H\&E scale bar $=50 \mu \mathrm{m}$; (D) The number of mitotic cells per tumour section from the negative control, AF2240-i-treated, and rAF-IL12-treated after 28-days of treatment. Data are presented as mean \pm S.E.M. of triplicate determinations. Mean values with statistical difference at $p \leq 0.05$ between groups are indicated with *. 


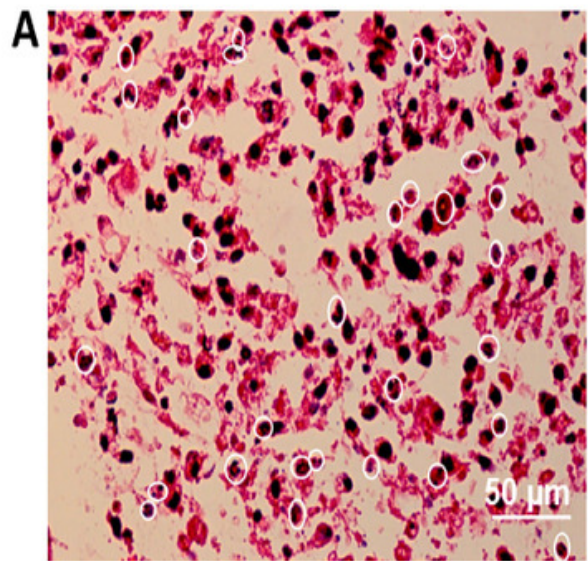

Negative control/Untreated
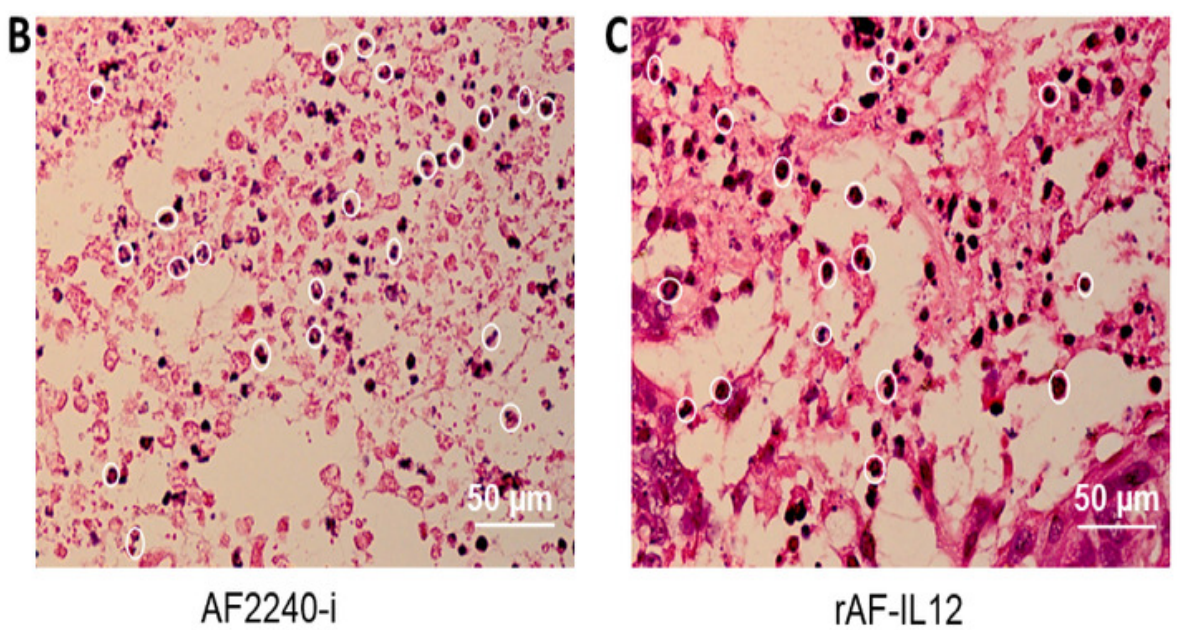

IAF-IL12

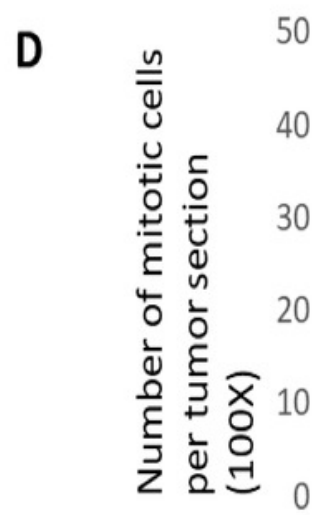

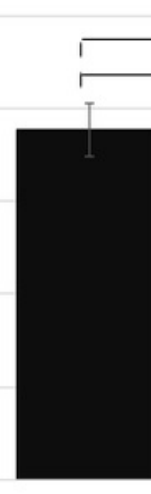

Negative Control

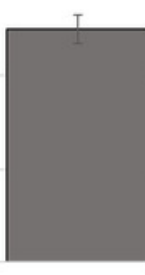

AF2240-i

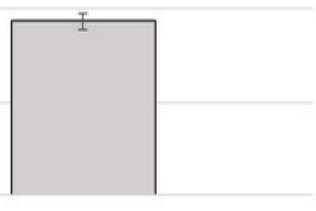

rAF-IL12 


\section{Table $\mathbf{1}$ (on next page)}

$\mathrm{EC}_{50}$ (half-maximal inhibitory concentration, HA unit) of AF2240-i and rAF-IL12 in HT29 and 3 T3 cells 72 -h post-infection.

$\mathrm{EC}_{50}$ (half-maximal inhibitory concentration, HA unit) of AF2240-i and rAF-IL12 in HT29 and 3T3 cells 72-h post-infection. 
1 Table 1. Data from tissue culture infective dose 50 (TCID $\left.{ }_{50}\right)$ assay of AF2240-i and rAF-

2 IL12 in HT29 cells 120-h post-infection.

$\begin{array}{ccc}\begin{array}{c}\text { Column number in } \\ \text { 96-well plate }\end{array} & \begin{array}{c}\log _{10} \text { titre of virus } \\ \text { dilution }\end{array} & \begin{array}{c}\text { Observed cytopathic effect (CPE) } \\ \text { percentage }(\%)\end{array}\end{array}$

96-well plate dilution percentage $(\%)$

AF2240-i rAF-IL12

\begin{tabular}{cccc}
\hline $\mathbf{A}$ & 0 & $4 / 4 \times 100=100$ & $4 / 4 \times 100=100$ \\
\hline $\mathbf{B}$ & -1 & $4 / 4 \times 100=100$ & $4 / 4 \times 100=100$ \\
\hline $\mathbf{C}$ & -2 & $4 / 4 \times 100=100$ & $4 / 4 \times 100=100$ \\
\hline $\mathbf{D}$ & -3 & $4 / 4 \times 100=100$ & $4 / 4 \times 100=100$ \\
\hline $\mathbf{E}$ & -4 & $0 / 4 \times 100=0$ & $1 / 4 \times 100=25$ \\
\hline $\mathbf{F}$ & -5 & $0 / 4 \times 100=0$ & $0 / 4 \times 100=0$ \\
\hline $\mathbf{G}$ & -6 & $0 / 4 \times 100=0$ & $0 / 4 \times 100=0$ \\
\hline $\mathbf{H}$ & No virus (negative & $0 / 4 \times 100=0$ & $0 / 4 \times 100=0$ \\
& control) & & \\
\hline
\end{tabular}

3 The TCID $_{50}$ was calculated based on the Reed and Muench method. The difference of algorithm 4 of AF2240-i-infected cells $=(100-50) /(100-0)=0.50 ; \log _{10} 50 \%$ end-point dilution $=-3-(0.50)$ $5=-3.50 ; 50 \%$ end-point dilution $=10^{-3.50}$; the titre of the virus: $10^{3.50} \mathrm{TCID}_{50} / 0.1 \mathrm{~mL}=3.16 \mathrm{x}$ $610^{4} \mathrm{TCID}_{50} / \mathrm{mL}$. The difference of algorithm of rAF-IL12-infected cells $=(100-50) /(100-25)=$ $7 \quad 0.67 ; \log _{10} 50 \%$ end-point dilution $=-3-(0.67)=-3.67 ; 50 \%$ end-point dilution $=10^{-3.67}$; the 8 titre of the virus: $10^{3.67} \mathrm{TCID}_{50} / 0.1 \mathrm{~mL}=4.68 \times 10^{4} \mathrm{TCID}_{50} / \mathrm{mL}$. The $\mathrm{TCID}_{50}$ was presented as 9 mean from four replicate determinations. 


\section{Table 2 (on next page)}

ALP, AST, ALT and creatinine serum biochemistry profiles of normal, negative control, AF2240-i-, and rAF-IL12-treated colon cancer-challenged mice after 28-days of treatments.

ALP, AST, ALT and creatinine serum biochemistry profiles of normal, negative control, AF2240-i-, and rAF-IL12-treated colon cancer-challenged mice after 28-days of treatments. 
2 Table 2. EC $_{50}$ (half-maximal inhibitory concentration, HA unit) of AF2240-i and rAF-IL12 3 in HT29 and $3 T 3$ cells $72-h$ post-infection.

\begin{tabular}{ccc}
\hline Cell line & Virus treatment & $\begin{array}{c}\mathbf{E C}_{\mathbf{5 0}} \text { (half-maximal } \\
\text { inhibitory concentration, } \\
\text { HA unit) }\end{array}$ \\
\hline HT29 & AF2240-i & $128 \pm 1.16$ \\
\hline rT3 & rAF-IL12 & $110 \pm 0.58^{*}$ \\
\hline & AF2240-i & N/A \\
\hline & rAF-IL12 & N/A
\end{tabular}

4 Data are presented as mean \pm S.E.M from triplicate determinations. Statistically significant 5 differences between the means at $\mathrm{p}<0.05$ are indicated with *.

6 


\section{Table 3 (on next page)}

ALP, AST, ALT and creatinine serum biochemistry profiles.

ALP, AST, ALT and creatinine serum biochemistry profiles of normal, negative control, AF2240-i-, and rAF-IL12-treated colon cancer-challenged mice after 28-days of treatments. 
2 Table 3. ALP, AST, ALT and creatinine serum biochemistry profiles of normal, negative 3 control, AF2240-i-, and rAF-IL12-treated colon cancer-challenged mice after 28-days of 4 treatments.

$\begin{array}{lcccc} & \text { ALP (U/L) } & \text { AST (U/L) } & \text { ALT (U/L) } & \begin{array}{c}\text { Creatinine } \\ \text { (Umol/L) }\end{array} \\ \text { Normal } & 146.0 \pm 1.2 & 124.0 \pm 0.6 & 116.5 \pm 0.4 & 37.5 \pm 0.9 \\ \begin{array}{l}\text { Negative } \\ \text { control } \\ \text { AF2240-i }\end{array} & 187.7 \pm 2.2^{*} & 190.7 \pm 1.2^{*} & 148.0 \pm 2.3^{*} & 48.3 \pm 0.3^{*} \\ \text { rAF-IL12 } & 166.3 \pm 1.8^{* *} & 146.3 \pm 0.3^{* *} & 129.3 \pm 1.5^{* *} & 40.0 \pm 0.6 \\ & 151.0 \pm 0.6 & 144.0 \pm 0.6^{* *} & 121.0 \pm 0.7 & 39.3 \pm 1.5\end{array}$

5 Data are presented as mean \pm S.E.M from six mice per group. Mean values with statistical 6 difference at $\mathrm{p} \leq 0.05$ between groups are indicated with *. 